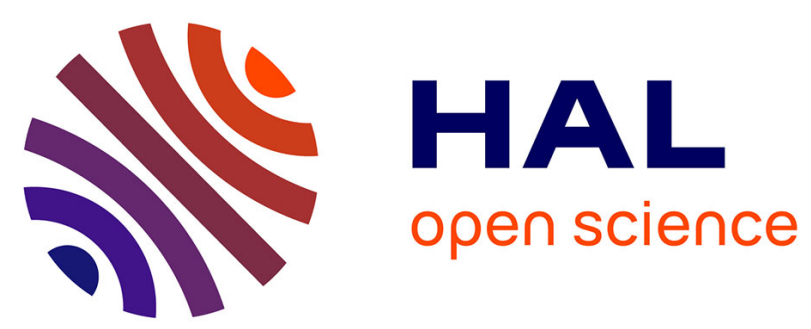

\title{
From the grafting of NHC-based Pd(II) complexes onto TiO 2 to the in situ generation of Mott-Schottky heterojunctions: the boosting effect in the Suzuki-Miyaura reaction. Do the evolved Pd NPs act as reservoirs?
}

F. Rataboul, Jonathan de Tovar, Laurent Djakovitch

\section{To cite this version:}

F. Rataboul, Jonathan de Tovar, Laurent Djakovitch. From the grafting of NHC-based Pd(II) complexes onto $\mathrm{TiO} 2$ to the in situ generation of Mott-Schottky heterojunctions: the boosting effect in the Suzuki-Miyaura reaction. Do the evolved Pd NPs act as reservoirs?. Journal of Catalysis, 2021, 398, pp.133-147. 10.1016/j.jcat.2021.04.016 . hal-03367096

\section{HAL Id: hal-03367096 \\ https://hal.science/hal-03367096}

Submitted on 6 Oct 2021

HAL is a multi-disciplinary open access archive for the deposit and dissemination of scientific research documents, whether they are published or not. The documents may come from teaching and research institutions in France or abroad, or from public or private research centers.
L'archive ouverte pluridisciplinaire HAL, est destinée au dépôt et à la diffusion de documents scientifiques de niveau recherche, publiés ou non, émanant des établissements d'enseignement et de recherche français ou étrangers, des laboratoires publics ou privés. 


\title{
From the grafting of $\mathrm{NHC}$-based $\mathrm{Pd}$ (II) complexes onto $\mathrm{TiO}_{2}$ to the in situ generation of Mott-Schottky heterojunctions: the boosting effect in the Suzuki-Miyaura reaction. Do the evolved Pd NPs act as reservoirs?
}

\author{
Jonathan De Tovar ${ }^{\mathrm{a}, \star}$, Franck Rataboul ${ }^{\mathrm{a}}$, Laurent Djakovitch ${ }^{\mathrm{a}, \star}$
}

[a] Dr. Jonathan De Tovar, Dr. Franck Rataboul, Dr. Laurent Djakovitch

Université de Lyon, Université Claude Bernard Lyon 1, CNRS, IRCELYON

F-69626, Villeurbanne, France

E-mail: Jonathan.DeTovar@ircelyon.univ-lyon1.fr; Laurent.Diakovitch@ircelyon.univ-lyon1.fr

Keywords: Suzuki-Miyaura, N-heterocyclic carbene, Palladium complexes, Palladium nanoparticles, Heterogeneous homogeneous catalysis, Titania

\begin{abstract}
The assumption that the real active species involved in the Suzuki-Miyaura reaction are homogeneous, heterogeneous or both is often proposed. However a lack of characterization of the true catalytic entities and their monitoring makes assumptions somewhat elusive. Here, with the aim of getting new insights into the formation of active species in the SuzukiMiyaura reaction, a family of palladium(II) complexes bearing bis(NHC) ligands was synthesized for immobilization at the surface of $\mathrm{TiO}_{2}$. The studies reveal that once the complexes are anchored onto $\mathrm{TiO}_{2}$, the mechanism governing the catalytic reaction is different from that observed for the non-anchored complexes. All complexes evolved to Pd NPs at the surface of $\mathrm{TiO}_{2}$ under reaction conditions and released $\mathrm{Pd}$ species in the liquid phase. Also, this reactivity was boosted by the in situ generation of Mott-Schottky heterojunctions, opening new routes towards the design of heterogenized catalysts for their further implementation in reverse-flow reactors.
\end{abstract}

\section{Introduction}

Palladium-based catalysts play an important role in C-C cross-coupling reactions. ${ }^{1}$ In particular, the impact of the Suzuki-Miyaura reaction has been immense since it has resulted to be one of the most efficient methodologies for the formation of biaryl derivatives. ${ }^{2}$

Despite the fact that many palladium-based complexes exhibiting high performances have been developed, the recovery and reuse of the catalytic system is still problematic. To tackle this issue the heterogenization of the complexes by immobilization onto a support is a possibility. ${ }^{3,4,5,6,7}$ However, the catalytic activity of such systems is usually lower than that of the homogeneous ones. Hence, the design of more active and stable heterogenized catalysts remains a priority for $\mathrm{C}-\mathrm{C}$ cross-coupling reactions.

Recently, we reported the excellent performances of novel N-heterocyclic carbene (NHC)-Pd catalysts (C1a-c, Scheme 1) for the Suzuki-Miyaura reaction and particularly demonstrated that the activity was strongly affected by the complex architecture. ${ }^{8}$ In the present work we describe a comprehensive study of the heterogenization of these systems for use in SuzukiMiyaura coupling. This corresponds to a further step towards the design of active and recyclable catalytic systems. For that we introduced a function at the ligand backbone allowing the grafting onto a support. It has been demonstrated for reported systems that 
the support clearly influences the catalytic performance. $9,10,11,12,13$ In this view, $\mathrm{TiO}_{2}$, exhibiting good thermal, mechanical and chemical stabilities can be regarded as a promising candidate. Therefore we particularly followed here the evolution of $\mathrm{TiO}_{2}$-heterogenized palladium complexes of the type $\mathrm{PdBr}_{2}(L \cap L)$, in which $L \cap L$ is a chelating bis(benzimidazol-2ylidene) ligand. We aimed at identifying their catalytic performances and the nature of the active species generated from such complexes. For that we evaluated the effect of the space-length $(\Omega)$ of the ligand, the reaction temperature, and the recyclability of the new catalytic system.

\section{Results and discussion}

\subsection{Synthesis and characterization of ligands and complexes}

The synthetic pathway to form the hybrid materials is presented in Scheme 1. It is based on the linkage of two benzimidazole 1 moieties giving bisbenzimidazolealkanes $2 a-c^{14}$ followed by an alkylation with diethyl (3-bromopropyl)phosphonate leading to ligands 3a-c. These were fully characterized by ${ }^{1} \mathrm{H},{ }^{13} \mathrm{C}$ and ${ }^{31} \mathrm{P}$ NMR spectroscopies (1D and 2D spectra, see Experimental section, Figures S1-S3). Here note that ${ }^{1} \mathrm{H} N M R$ indicates a $\mathrm{C}_{2}$ symmetry in solution for the three ligands in which not only the two alkylated benzimidazolium moieties are equivalent but also bridge protons. All ligands have also been characterized by HR-ESIMS (Figures S4-S6) and IR spectroscopies (Figures S7-S9).

a)

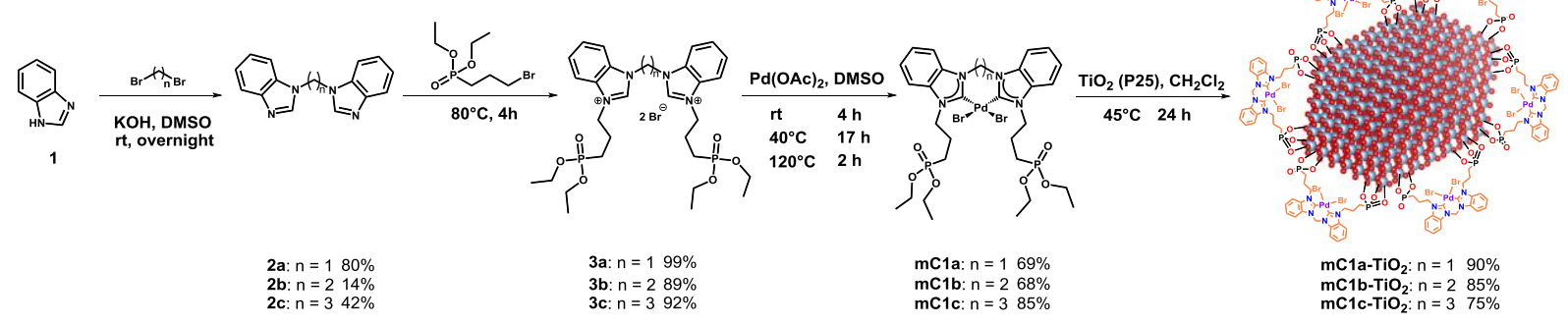

b)

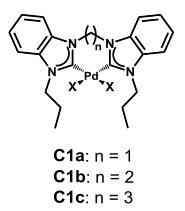

Scheme 1. (a) Synthetic pathway for 3a-c ligands, mC1a-c complexes and mC1a-c- $\mathrm{TiO}_{2}$ hybrid catalysts. (b) C1ac complexes prepared in our previous study (reference 8).

Next, coordination to $\mathrm{Pd}(\mathrm{OAc})_{2}$ gave corresponding palladium(II) molecular complexes mC1a-c obtained as air- and moisture-stable solids. ${ }^{1} \mathrm{H}$ NMR spectra show that the downfield signals ( $\sim 9-11 \mathrm{ppm}$ ) of acidic protons for the different bisbenzimidazolium salts are no longer present (Figures S10-S12), confirming the deprotonation of the benzimidazolium moiety upon formation of biscarbene complexes. ${ }^{15}$ Additionally, all methylene protons of the bridges become diastereotopic due to ligand coordination and retention of the bend-boat conformation in these complexes. ${ }^{16}$ The observed broadening of these resonances has been attributed to the fluxionality of the seven- or eight-membered chelate rings. ${ }^{17}$ Interestingly, 
the methylene protons of propyl chains became also diastereotopic because of the $\mathrm{H} \cdots \mathrm{Br}$ interaction with bromido ligands, these methylene protons being shifted downfield (4-5 $\mathrm{ppm})$. The formation of the mC1a-c mononuclear complexes was also supported by their high-resolution ESI mass spectra at $m / z=892.9868,907.0019$ and 921.0180 for the molecular cations $[\mathrm{M}+\mathrm{Na}]^{+}$(mC1a, $\mathbf{m C 1 b}$ and $\mathbf{m C 1 c}$, respectively, Figures S13-S16), fitting with their simulated spectra. Finally, the complexes have been complementary characterized by IR spectroscopy (Figures S16-S18).

\subsection{Anchoring of the complexes on $\mathrm{TiO}_{2}$}

The next step consisted in grafting the mC1a-c $\mathrm{Pd}(\mathrm{II})$ complexes at the surface of $\mathrm{TiO}_{2}(\mathrm{P}-25$,

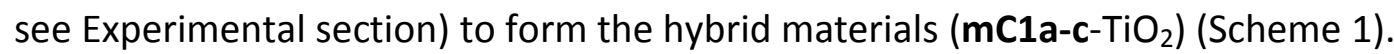

Phosphonate anchoring groups are well known to efficiently interact with metal oxide surfaces. ${ }^{18,19,20}$ For instance, the cleavage of P-OEt bonds on $\mathrm{TiO}_{2}$ has already been reported in the case of diethyl phenylphosphonate. ${ }^{21}$ Here the grafting was performed following Guerrero et al. ${ }^{22}$ procedure. $\mathrm{A} \mathrm{TiO}_{2}$ suspension in dichloromethane containing the palladium(II) complex was stirred at $45^{\circ} \mathrm{C}$ for $24 \mathrm{~h}$. Then, dispersion was filtered off, washed and dried at $120^{\circ} \mathrm{C}$ under vacuum. ICP-OES analyses indicated that the grafting was achieved with 68 to $82 \%$ yield (Table 1) relative to the maximum expected $0.28 \mathrm{wt} \% \mathrm{Pd}$. Note that increasing the starting amount of $\mathrm{Pd}(\mathrm{II})$ complexes did not increase the coverage. Also, the $\mathrm{Pd} / \mathrm{P}$ ratios present in the hybrid materials match with their non-grafted counterparts (see Experimental section) indicating that the integrity of the complexes remained upon grafting. The anchoring through the phosphonate moiety of mC1a-c complexes was attested by ATRIR spectroscopy (Figures 1 and S19-S20). As shown in Figure 1 the mC1a complex presents two absorption bands at $1222 \mathrm{~cm}^{-1}$ and $1014 \mathrm{~cm}^{-1}$ corresponding to the free $\mathrm{P}=\mathrm{O}$ and $\mathrm{P}-\mathrm{O}-\mathrm{C}$ units, respectively. ${ }^{22}$ No free $\mathrm{P}=\mathrm{O}$ and $\mathrm{P}-\mathrm{O}-\mathrm{C}$ bands are visible for $\mathbf{m C 1 a -} \mathrm{TiO}_{2}$ while appeared a band at $1037 \mathrm{~cm}^{-1}$ attributed to $-\mathrm{P}-\mathrm{O}-\mathrm{Ti}_{\text {bond }}{ }^{22,23}$.

Table 1. Pd (wt\%) and grafting (\%) for the $\mathrm{mC1a}-\mathrm{c}-\mathrm{TiO}_{2}$.

\begin{tabular}{lll} 
Hybrid Catalyst & $\mathrm{Pd}(\mathrm{wt} \%)$ & $\begin{array}{l}\text { Grafting } \\
(\%)\end{array}$ \\
\hline $\mathbf{m C 1 a}-\mathrm{TiO}_{2}$ & 0.23 & 82 \\
$\mathbf{m C 1 b}-\mathrm{TiO}_{2}$ & 0.21 & 75 \\
$\mathbf{m C 1 c}-\mathrm{TiO}_{2}$ & 0.19 & 68 \\
\hline
\end{tabular}




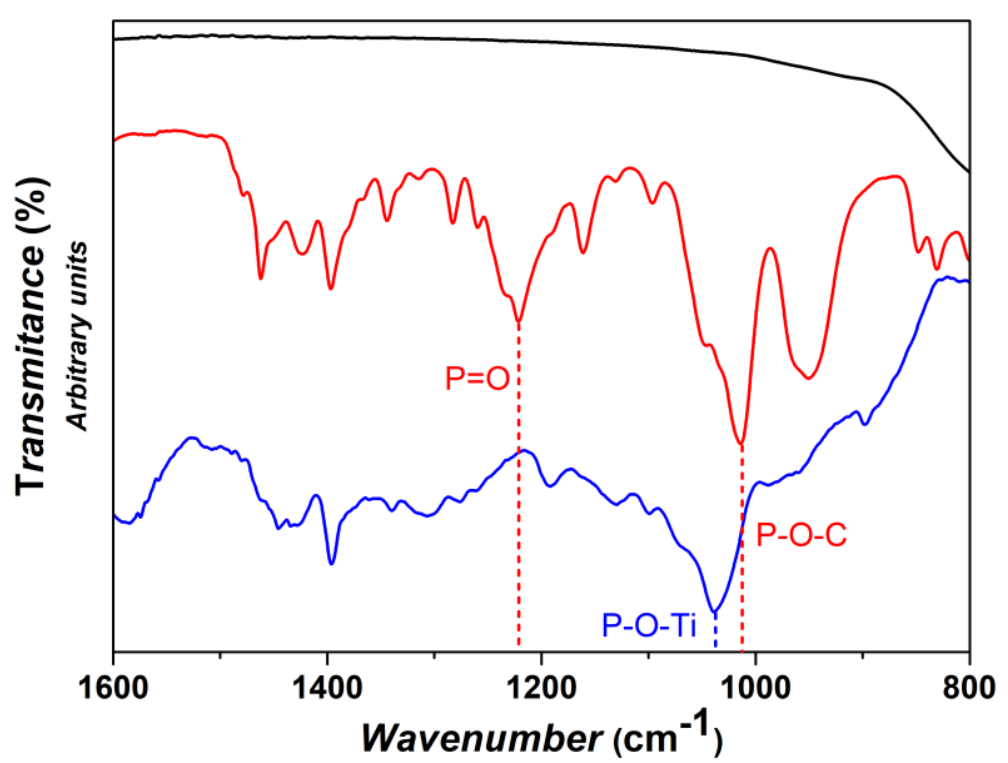

Figure 1. Overlay of ATR-IR spectra of $\mathrm{TiO}_{2}$ (black), $\mathbf{m C 1 a}$ complex (red) and $\mathbf{m C 1 a - T i O}$ hybrid material (blue). The transmittance of each sample has been shifted along the $y$-axis for comparison purposes.

Additionally, the ${ }^{31} \mathrm{P}$ HPDEC solid-state NMR spectra of the hybrid materials (Figures 2 and S21-S22) were similar regardless of the complex. The major resonance at $26.1 \mathrm{ppm}$ is ascribed to tridentate phosphonate sites $-\mathrm{P}(\mathrm{OTi})_{3}$. The presence of an additional resonance near $31.5 \mathrm{ppm}$ points to another bonding mode, which is likely to be bidentate phosphonate $-\mathrm{P}(\mathrm{OTi})_{2}(\mathrm{OEt})$ sites. ${ }^{13} \mathrm{C} \mathrm{CP}-\mathrm{MAS}$ NMR spectra show a good match with the free mC1a-c complexes (Figures S23-S25).

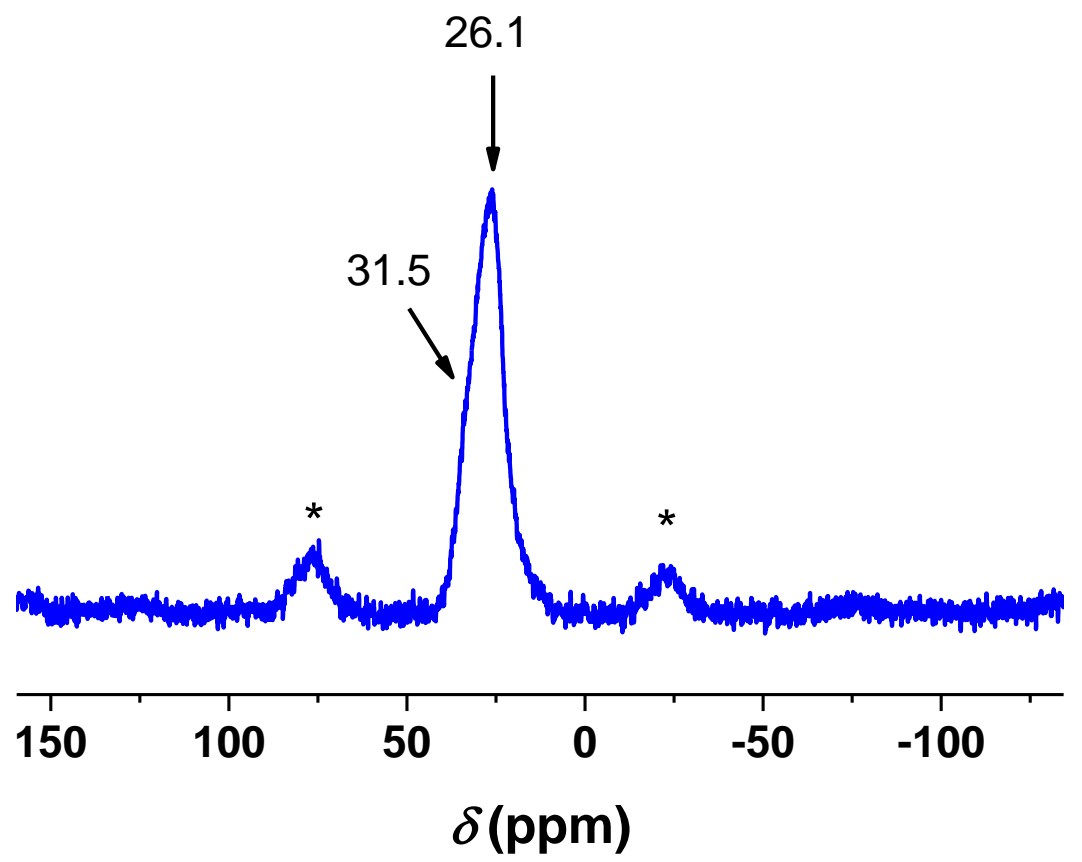

Figure 2. ${ }^{31} \mathrm{P}$ HPDEC NMR spectrum of $\mathbf{m C 1 a}-\mathrm{TiO}_{2}$ hybrid material. * Spinning bands. 
TEM analyses of the hybrid nanomaterials revealed the presence of $\mathrm{TiO}_{2}$ nanoobjects with a mean size of $21 \mathrm{~nm}$ (Figure S26). Therefore the initial size and morphology of $\mathrm{TiO}_{2}$ were maintained after anchoring the mC1a-c without the decomposition of the complexes. The $\mathbf{m C 1} \mathbf{b}-\mathrm{TiO}_{2}$ and $\mathbf{m C 1} \mathbf{c}-\mathrm{TiO}_{2}$ hybrid nanomaterials were characterized accordingly, with very similar results to $\mathrm{mC1a}^{-\mathrm{TiO}_{2}}$ (Figures S19-S22 and S24-S26).

To sum-up this section, easily obtained $\mathrm{Pd}$ (II) complexes bearing phosphonate moieties have been prepared and successfully grafted onto $\mathrm{TiO}_{2}$ surface giving new hybrid nanomaterials.

\subsection{Catalytic performance studies}

The different prepared hybrid nanomaterials have been evaluated as catalysts for the model reaction depicted in Scheme 2, and compared with the free C1a-c palladium(II) molecular complexes (Scheme 1). We aimed at performing the reactions under mild conditions and short times using a low catalyst loading.

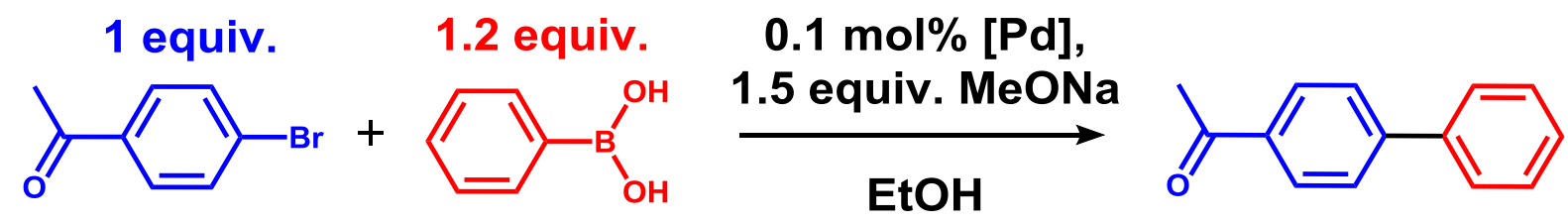

Scheme 2. Suzuki-Miyaura reaction studied in this work.

$p$-Bromoacetophenone and phenylboronic acid were selected as substrates in order to discriminate cross-coupling from homocouplings. Neither the homocoupling of phenylboronic acid nor that of $p$-bromoacetophenone nor dehalogenation of $p$ bromoacetophenone were observed. Thus, since the formation of $p$-acetylbiphenyl was exclusive, conversions and yields were considered as equal values. Once conditions optimized, phenylboronic acid $\left(\mathrm{PhB}(\mathrm{OH})_{2} / \mathrm{Pd}=1200\right)$, $p$-bromoacetophenone (substrate/ $\mathrm{Pd}=$ 1000 ), and sodium methoxide (base $/ \mathrm{Pd}=1500$ ) were employed in absolute ethanol as solvent to assure a better solubility of the former. Final conversions, turnover numbers (TONs), turnover frequencies (TOFs), initial activities (iTOFs) with induction periods are reported in Table 2 (see Experimental section for determination).

In order to compare the catalytic performance of grafted and non-grafted complexes, reactions were performed at two different temperatures of $60^{\circ} \mathrm{C}$ and $25^{\circ} \mathrm{C}$ using the same $\mathrm{Pd}$ loading (Figures 3-4).

As previously observed for the free C1a-c complexes, ${ }^{8}$ depletion was noted in the first 10 min (Figure 3a) while complete conversions were achieved for all $\mathbf{m C 1 a - c - T i O}$ (Figure $3 b$ ). Surprisingly and contrary to C1a-c catalysts, the performances observed for the hybrid materials led to higher iTOFs for larger bridges (Table 1). Therefore, once the complexes are grafted, the space-length $(\cap)$ affects the transformation through an opposite effect. From here, it can be inferred a different catalytic mechanism when heterogenizing the mC1a-c catalysts (vide infra, sections 2.4-2.5). 
Interestingly, the new $\mathbf{m C 1} \mathbf{b}-\mathrm{TiO}_{2}$ and $\mathbf{m C 1 c}-\mathrm{TiO}_{2}$ materials gave moderate to good yield when decreasing the temperature to $25^{\circ} \mathrm{C}$ whereas $\mathrm{C} 1 \mathrm{a}-\mathrm{C}$ complexes showed almost no activity (Figure 4). This confirms a higher efficiency of the heterogeneous catalysts.

The formation of Pd NPs from free C1a-c complexes was already observed in our previous work under the same catalytic conditions. ${ }^{8}$ Surprisingly, it appears here that even when C1ac complexes are immobilized, Pd NPs were formed during the reaction as revealed by TEM images. Note that they are present not only at the surface of $\mathrm{TiO}_{2}$ but also on the holey carbon of the TEM grid (Figures S27-S28 and Table S1). These particles exhibited a monodisperse population of spherical NPs with a narrow size-distribution. Interestingly, all NPs display a mean size lower than those evolved directly from the free C1a-c complexes. ${ }^{8}$ Additionally, smaller NPs were observed after catalysis at higher temperatures. Thus, increasing the temperature greatly enhanced the complex decomposition followed by cluster formation as well as favoring the leaching of highly active Pd species from grafted $\mathrm{Pd}$ complexes or in situ formed Pd NPs.

a)

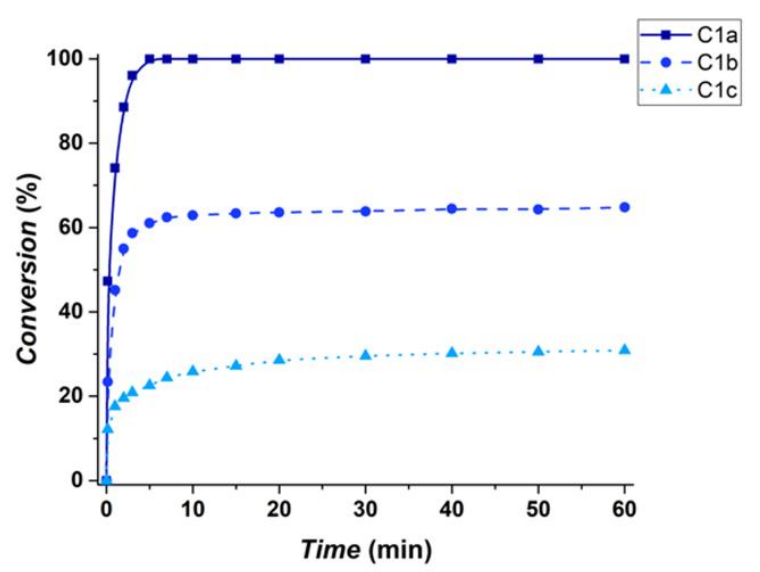

b)

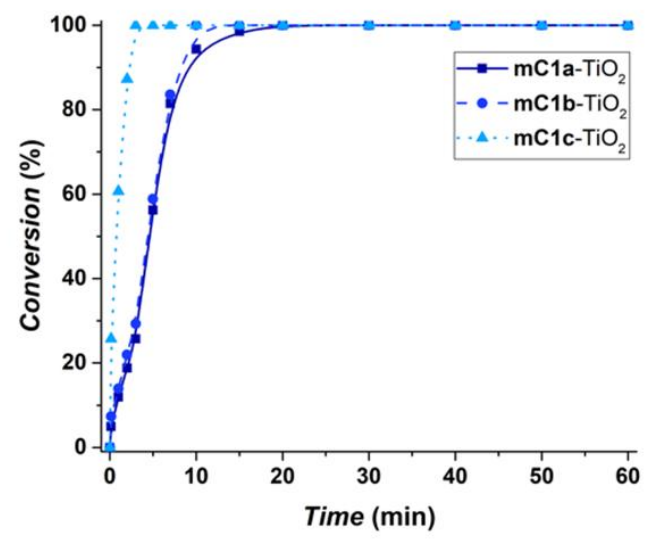

Figure 3. Conversion versus the time for the coupling reaction of $p$-bromoacetophenone with phenylboronic acid using (a) $\mathrm{Cla}-\mathrm{c}$ and (b) $\mathrm{mCla}^{\mathrm{a}-\mathrm{c}-\mathrm{TiO}_{2}}$ catalysts at $60^{\circ} \mathrm{C}$.

a)

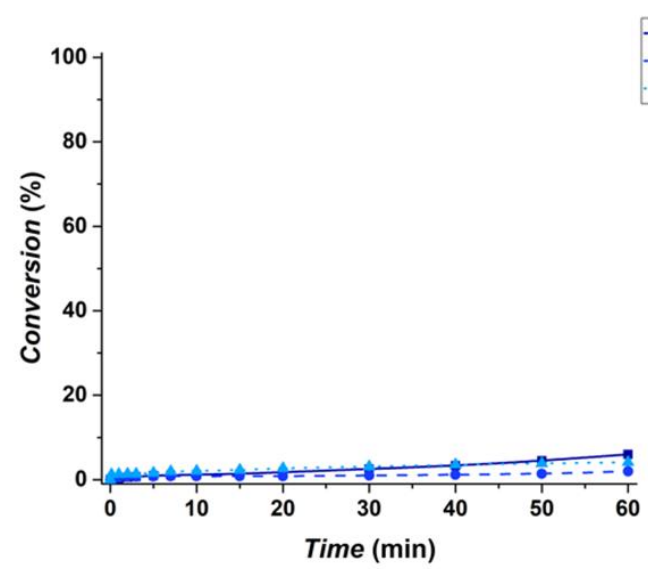

b)

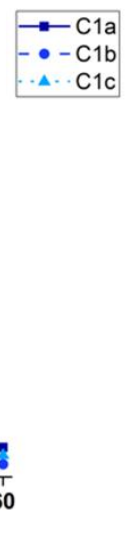

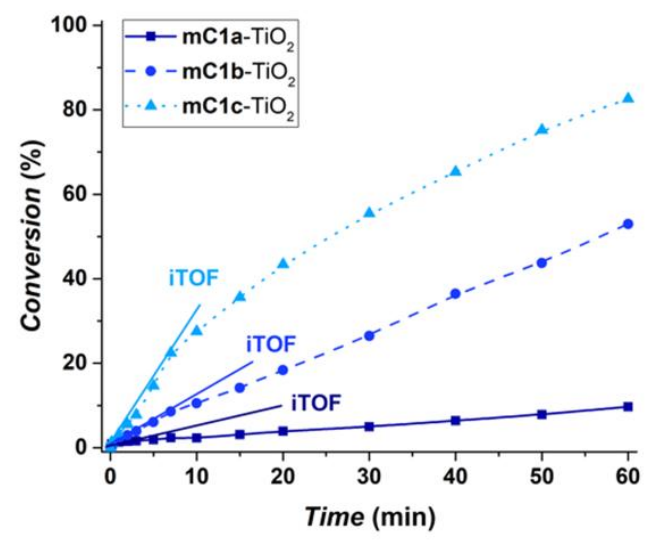

Figure 4. Conversion versus the time for the coupling reaction of $p$-bromoacetophenone with phenylboronic

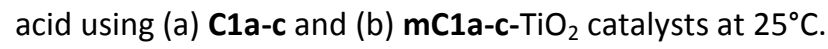


Table 2. iTOF, conversion, TON and TOF values for the Suzuki-Miyaura reaction of $p$-bromocetophenone with phenylboronic acid.

\begin{tabular}{|c|c|c|c|c|c|c|c|c|c|}
\hline \multirow[t]{3}{*}{ Entry } & \multirow[t]{3}{*}{ Catalyst } & \multicolumn{8}{|c|}{ p-bromoacetophenone } \\
\hline & & \multicolumn{4}{|l|}{$60^{\circ} \mathrm{C}$} & \multicolumn{4}{|l|}{$25^{\circ} \mathrm{C}$} \\
\hline & & $\begin{array}{l}\text { iTOF }\left(\left(\mathrm{mol}_{\text {product }}\right.\right. \\
\left.\cdot \mathrm{mol} \mathrm{Pd}^{-1} \cdot \mathrm{min}^{-1}\right)\end{array}$ & Conv. & TON & $\operatorname{TOF}\left(h^{-1}\right)$ & $\begin{array}{l}\text { iTOF }\left(\left(\mathrm{mol}_{\text {product }}\right.\right. \\
\left.\cdot \mathrm{mol} \mathrm{Pd}^{-1} \cdot \mathrm{min}^{-1}\right)\end{array}$ & Conv. & TON & $\operatorname{TOF}\left(\mathrm{h}^{-1}\right)$ \\
\hline 1 & C1a & 611 & 100 & 1000 & 12000 & 2 & 6 & 60 & 60 \\
\hline 2 & C1b & 294 & 65 & 648 & 388 & 1 & 2 & 19 & 19 \\
\hline 3 & C1c & 90 & 31 & 309 & 927 & 0.4 & 4 & 41 & 41 \\
\hline 4 & $\mathrm{mC} \mathrm{a}-\mathrm{TiO}_{2}$ & 169 & 100 & 1000 & 3000 & 7 & 10 & 97 & 97 \\
\hline 5 & $\mathrm{mC}_{1 \mathrm{~b}-\mathrm{TiO}_{2}}$ & 253 & 100 & 1000 & 6000 & 33 & 53 & 530 & 530 \\
\hline 6 & $\mathrm{mC}_{1 \mathrm{c}}-\mathrm{TiO}_{2}$ & 1914 & 100 & 1000 & 20000 & 58 & 83 & 826 & 826 \\
\hline
\end{tabular}

$8 \times 10^{-4} \mathrm{mmol} \mathrm{Pd}, 0.8 \mathrm{mmol} p$-bromoacetophenone, $1 \mathrm{mmol}$ phenylboronic acid and $1.2 \mathrm{mmol} \mathrm{MeONa}$ in $16 \mathrm{~mL}$ absolute EtOH. Conversion after $1 \mathrm{~h}$ reaction.

\subsection{Leaching studies}

Having demonstrated the superior performance in the presence of the $\mathbf{m C 1}-\mathrm{TiO}_{2}$ catalyst for the Suzuki-Miyaura cross-coupling reaction, we addressed the leaching of the Pd-species in solution during the catalytic reaction, suspected by the formation of Pd NPs. Leaching is often observed when supported catalysts are used in such cross-coupling reactions ${ }^{24,25,26}$ determined following several methodologies. ${ }^{24,27}$ Among them the hot-filtration method provides reliable information. The Pd leaching was examined for the coupling reaction at $25^{\circ} \mathrm{C}$ using the hot-filtration method: after $15 \mathrm{~min}$ of a standard catalytic run (corresponding to $c a$. $35 \%$ conversion, Figure 5), the reaction mixture was filtered to remove $\mathbf{m C} \mathbf{c}-\mathrm{TiO}_{2}$ solid leaving a clear filtrate (see Experimental section). The latter was then used as reaction medium and analyzed over time. Here, the activity was completely stopped after filtration (Figure 5). This suggests that (1) no complex degrafting occurred during this period, or (2) leached species if any were not active at $25^{\circ} \mathrm{C}$, or (3) the catalytic performance could be due to some Pd NPs formed from catalyst decomposition in the first $15 \mathrm{~min}$. No Pd was found in the filtrate by ICP-OES analysis but could be present at concentration less than $0.01 \mathrm{ppm}$, that is the detection limit. With these results, to discard between the different hypotheses, we decided to increase the reaction temperature to $60^{\circ} \mathrm{C}$ when using the filtrate mixture. Interestingly, at this temperature the reaction was reinitiated giving a complete conversion after 20 minutes (Figure 5). This result indicates clearly that Pd species released from the immobilized palladium system or from evolved Pd NPs are present in solution. These Pdspecies play a significant role in the catalyst activity at $60^{\circ} \mathrm{C}$, through homogeneous pathways. Thus, these $\mathrm{Pd}$ species, despite present at a very low concentration, could be the true catalytic entities and would then be redeposited on the functionalized $\mathrm{TiO}_{2}$ or merged as Pd NPs at reaction completion. 


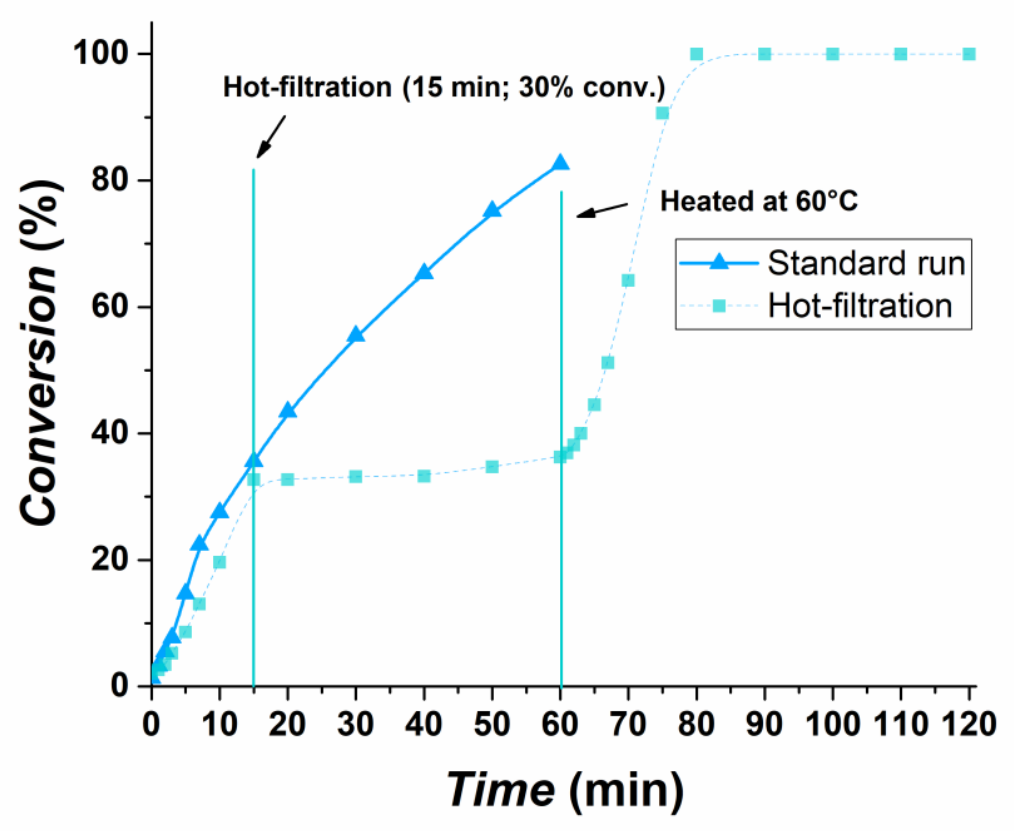

Figure 5. Activity of $\mathrm{mC1} \mathbf{c}-\mathrm{TiO}_{2}$ catalyst after hot-filtration at $\mathrm{ca}$. $30 \%$ conversion versus standard catalytic run.

\subsection{Recycling studies}

The recycling of the catalyst was examined for the coupling at $60^{\circ} \mathrm{C}$ in the first $10 \mathrm{~min}$. This procedure, described elsewhere, ${ }^{28,29}$ was performed as follows: at the completion of a $1^{\text {st }}$ run using fresh $\mathbf{m C 1} \mathbf{c}-\mathrm{TiO}_{2}$, new reagents were added to the reaction mixture and the conversion was set to 0 at the corresponding "initial time" for the next run of the catalyst (method A, see Experimental section). Figure 6 shows that an activation occurs after the $1^{\text {st }}$ run of the catalyst as indicated by determination of the initial rate iTOF $1=1914 \mathrm{~min}^{-1}$ for the $1^{\text {st }}$ run and greater $\mathrm{TTOF}_{2}=5532 \mathrm{~min}^{-1}$ for the $2^{\text {nd }}$ run (Table 3 ). On a one hand, only small difference was observed in terms of conversions which was completely achieved within 3 min for the $1^{\text {st }}$ run whereas the $2^{\text {nd }}$ run needed $10 \mathrm{~min}$. To confirm the results the procedure was repeated twice. Under these conditions, comparable reaction rates $\mathrm{iTOF}_{3}$ and $\mathrm{iTOF}_{4}$ to that for $2^{\text {nd }}$ run were observed (Table 3 ) indicating that no "re-activation" of the catalyst was required. On another hand, longer reaction time to achieve quantitative conversions over successive recyclings can be attributed to the visually observed change of the viscosity of the reaction mixture (increased ionic strength), preventing efficient diffusion of the substrates to the active sites. 


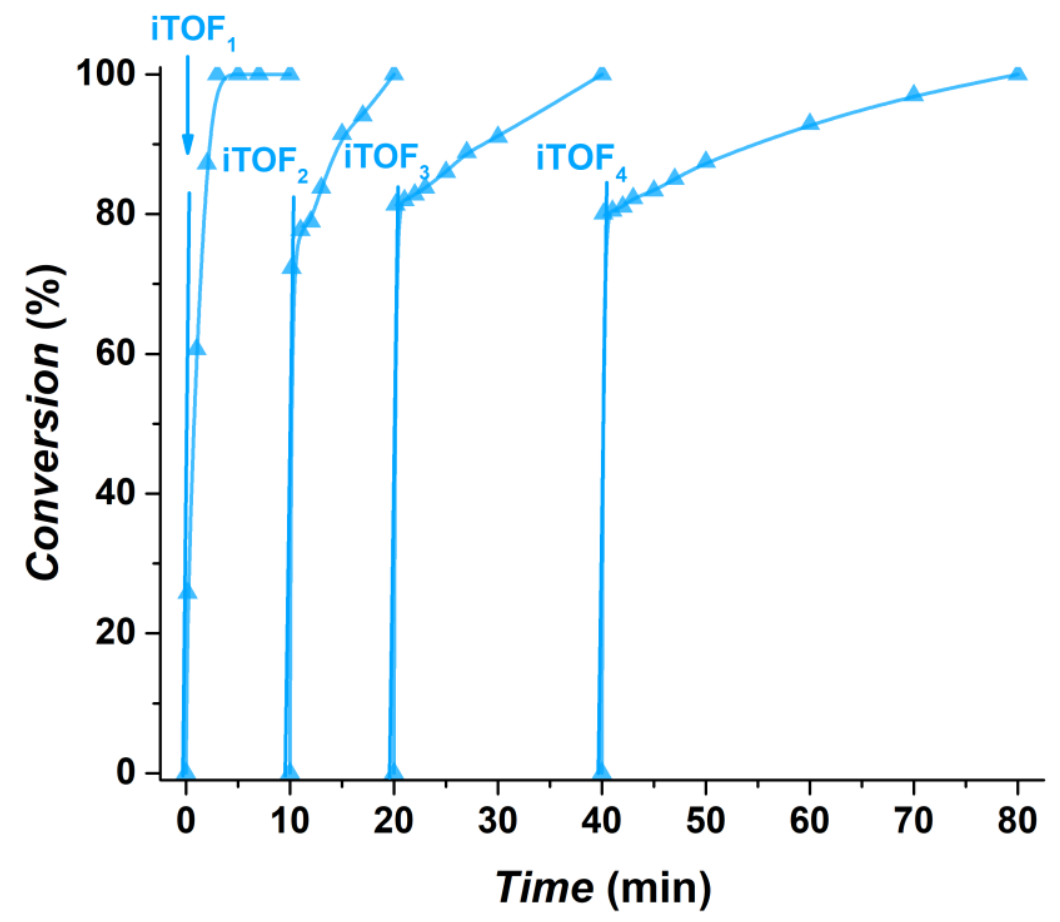

Figure 6. Recyclability (method A) of the $\mathrm{mCl} \mathrm{c}-\mathrm{TiO}_{2}$ catalyst for the $\mathrm{C}-\mathrm{C}$ coupling of $p$-bromoacetophenone and phenylboronic acid. Reaction conditions: $8 \times 10^{-4} \mathrm{mmol} \mathrm{Pd}, 0.8 \mathrm{mmol} p$-bromoacetophenone, $1 \mathrm{mmol}$ phenylboronic acid, $1.2 \mathrm{mmol} \mathrm{MeONa}, 16 \mathrm{~mL}$ absolute EtOH, $60^{\circ} \mathrm{C}$.

Table 3. Catalyst activities, conversion, TON and TOF values for the Suzuki-Miyaura reaction of $p$ bromoacetophenone and phenylboronic acid when recycling $\mathrm{mCl} \mathrm{c}-\mathrm{TiO}_{2}$ (method $\mathrm{A}$ ).

\begin{tabular}{lllll} 
Entry & $\begin{array}{l}\text { iTOF }\left(\mathrm{mol} \text { product } \cdot \mathrm{mol} \mathrm{Pd}^{-1} \cdot \mathrm{min}^{-}\right. \\
1^{1}\end{array}$ & Conv. & TON & TOF $\left(\mathrm{h}^{-1}\right)$ \\
\hline $1^{\text {st }}$ run & 1914 & 100 & 1000 & 20000 \\
$2^{\text {nd }}$ run & 5532 & 100 & 1000 & 6000 \\
$3^{\text {rd }}$ run & 6235 & 100 & 1000 & 3000 \\
$4^{\text {th }}$ run & 6137 & 100 & 1000 & 1500 \\
\hline
\end{tabular}

Reaction conditions: $8 \times 10^{-4} \mathrm{mmol} \mathrm{Pd}, 0.8 \mathrm{mmol} p$-bromoacetophenone, $1 \mathrm{mmol}$ phenylboronic acid and $1.2 \mathrm{mmol} \mathrm{MeONa}$ in $16 \mathrm{~mL}$ absolute EtOH. Conversion after $1 \mathrm{~h}$ reaction.

In order to avoid the increased viscosity of the reaction media, the recycling tests of mC1c$\mathrm{TiO}_{2}$ were also performed by centrifugation of the reaction crude for recovery of the solid after each run (method B, see Experimental section). As shown in Figure 7 and Table 4, lower iTOFs were obtained when reusing the separated catalyst and thus longer times were required to achieve complete conversions. 


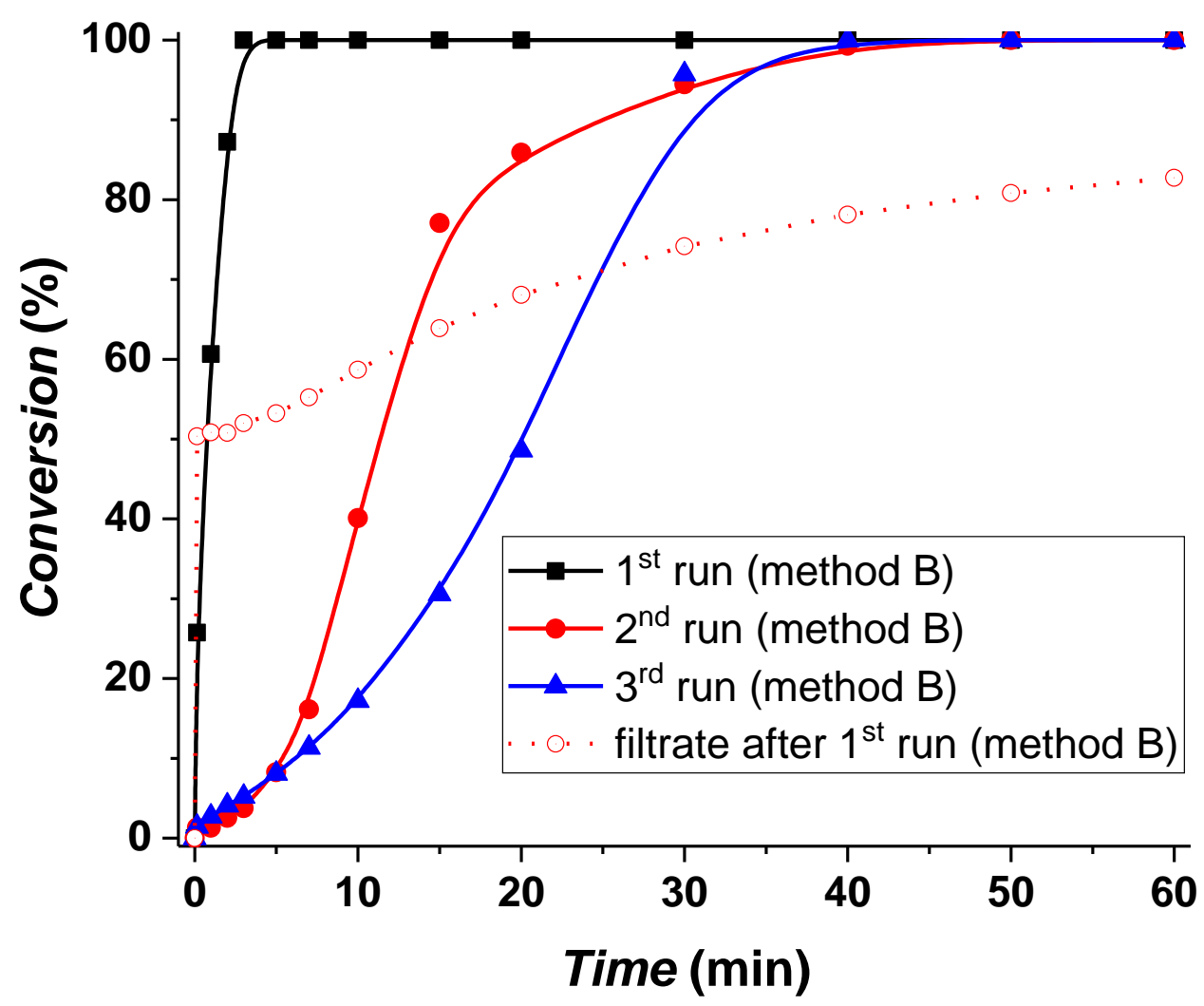

Figure 7. Recyclability (method $\mathrm{B}$ ) of the $\mathrm{mC1} \mathrm{c}-\mathrm{TiO}_{2}$ catalyst for the $\mathrm{C}-\mathrm{C}$ coupling of $p$-bromoacetophenone and phenylboronic acid. Reaction conditions: $8 \times 10^{-4} \mathrm{mmol} \mathrm{Pd}, 0.8 \mathrm{mmol} p$-bromoacetophenone, $1 \mathrm{mmol}$ phenylboronic acid, $1.2 \mathrm{mmol} \mathrm{MeONa}, 16 \mathrm{~mL}$ absolute EtOH, $60^{\circ} \mathrm{C}$.

Table 4. Catalyst activities, conversion, TON and TOF values for the Suzuki-Miyaura reaction of $p$ bromoacetophenone and phenylboronic acid when recycling $\mathrm{mClc}^{-} \mathrm{TiO}_{2}$ (method $\mathrm{B}$ ).

\begin{tabular}{lllll} 
Entry & iTOF $\left(\mathrm{mol}\right.$ product $\left.\cdot \mathrm{mol} \mathrm{Pd}^{-1} \cdot \mathrm{min}^{-1}\right)$ & Conv. & TON & TOF $\left(\mathrm{h}^{-1}\right)$ \\
\hline $1^{\text {st }}$ run & 1914 & 100 & 1000 & 20000 \\
$2^{\text {nd }}$ run & 108 & 100 & 1000 & 1500 \\
$3^{\text {rd }}$ run & 102 & 100 & 1000 & 1500 \\
\hline
\end{tabular}

Reaction conditions: $8 \times 10^{-4} \mathrm{mmol} \mathrm{Pd}, 0.8 \mathrm{mmol} p$-bromoacetophenone, $1 \mathrm{mmol}$ phenylboronic acid and $1.2 \mathrm{mmol} \mathrm{MeONa}$ in $16 \mathrm{~mL}$ absolute $\mathrm{EtOH}$. Conversion after $1 \mathrm{~h}$ reaction.

Interestingly, the filtrate collected after the $1^{\text {st }}$ run (method B) was tested for possible catalytic activity. As shown in Figure 7, it reveals, as already observed for leaching studies, the presence of species able to catalyze the reaction, at $60^{\circ} \mathrm{C}$, but rapidly deactivating as shown from the strong inflexion observed after few minutes, leading to slower overall transformation. In parallel, a complete conversion was achieved by using the filtered catalyst recovered after a $1^{\text {st }}$ run (method $\mathrm{B}$ ). Comparing to the recycling method $\mathrm{A}$ used previously when all species, i.e. dissolved $\mathrm{Pd}$-species and $\mathrm{Pd}$-species immobilized on $\mathrm{TiO}_{2}$, are present at the same time, it can be inferred that the catalytic performance of $\mathbf{m C 1 c}-\mathrm{TiO}_{2}$ comes from 
both, homogeneous and heterogeneous Pd-species. This can be observed in the $2^{\text {nd }}$ run when recycling the $\mathrm{mC1} \mathrm{c}-\mathrm{TiO}_{2}$ material by method $\mathrm{A}$ (Table $3,2^{\text {nd }}$ run, Figure 6 ). An equilibrium between the two natures of $\mathrm{Pd}$-species being more probably responsible for the higher behavior observed when performing recycling by the method $\mathrm{A}$. It is noteworthy to mention that the reduced efficiency of the isolated catalyst resulted from each run by method $B$ could also be due to a deactivation upon separation from the catalytic reaction. However, as demonstrated in Figures 6 and 7, the Pd species in the liquid phase play a pivotal role in the catalytic activity compared to the generated $\mathrm{Pd}$ species on $\mathrm{TiO}_{2}$.

\subsection{Fate of the catalyst and mechanism considerations}

To further study the fate of $\mathbf{m C 1}-\mathrm{TiO}_{2}$ under turnover conditions, the crude reaction mixture upon recycling (method B) was analyzed by TEM, EDX, XPS, UV-Vis, solid-state ${ }^{31} \mathrm{P}$ NMR and ICP-OES.

Figure 8 shows the evolution of the ${ }^{31} \mathrm{P}$ HPDEC NMR spectrum and indicates that the bidentate phosphonate moieties at $c a .31 .5 \mathrm{ppm}$ were partially hydrolyzed to yield a net tripodal anchoring at $c a .25 \mathrm{ppm}$. In parallel, TEM images reveal the presence of Pd NPs of $4.7 \pm 0.6 \mathrm{~nm}$ both at the surface of $\mathrm{TiO}_{2}$ and along the grid (Figure 8 and Table 5). After the $2^{\text {nd }}$ cycle, Pd NPs were only present at the surface of $\mathrm{TiO}_{2}$ showing two families of $4.3 \pm 1.0$ and $17.9 \pm 2.3 \mathrm{~nm}$. After the $3^{\text {rd }}$ cycle, a single family of Pd NPs of $4.3 \pm 0.9 \mathrm{~nm}$ was observed. This indicates that, in fact, the evolved Pd NPs at the surface of $\mathrm{TiO}_{2}$ act as reservoirs of active Pd species.
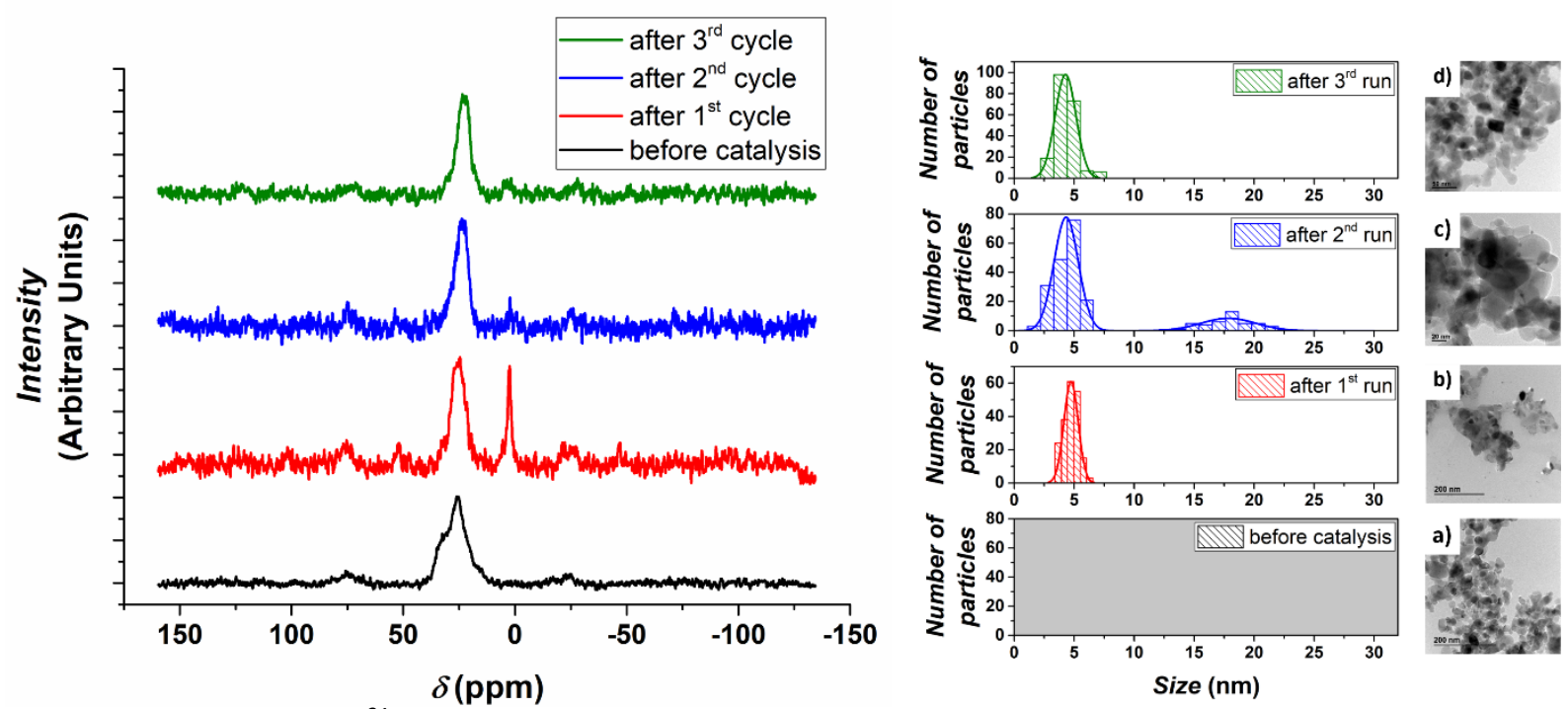

Figure 8. Evolution of the ${ }^{31} \mathrm{P}$ HPDEC NMR for the $\mathrm{mClc}^{-}-\mathrm{TiO}_{2}$ catalyst upon recycling and TEM images with their Pd NPs size histograms for each run (method B). 
Table 5. Evolution of the mean sizes and their standard deviations for Pd nanoparticles when recycling (method B) the $\mathbf{m C 1}$ - $-\mathrm{TiO}_{2}$ catalyst using $p$-bromoacetophenone as substrate at $60^{\circ} \mathrm{C}$.

\begin{tabular}{llll}
\hline Catalyst & Mean size \pm standard deviation $(\mathrm{nm})$ & $\mathrm{Pd}(\mathrm{wt} \%)$ & $\mathrm{P}(\mathrm{wt} \%)$ \\
\cline { 2 - 4 } $\mathbf{1}^{\text {st }}$ run & $4.7 \pm 0.6$ & 0.12 & 0.04 \\
$\mathbf{2}^{\text {nd }}$ run & $4.3 \pm 1.0 ; 17.9 \pm 2.3$ & 0.12 & 0.04 \\
$\mathbf{3}^{\text {rd }}$ run & $4.3 \pm 0.9$ & 0.10 & 0.04 \\
\hline
\end{tabular}

Reaction conditions: $8 \times 10^{-4} \mathrm{mmol} \mathrm{Pd}, 0.8 \mathrm{mmol} p$-bromoacetophenone, $1 \mathrm{mmol}$ phenylboronic acid and $1.2 \mathrm{mmol} \mathrm{MeONa}$ in $16 \mathrm{~mL}$ absolute EtOH. Data after $1 \mathrm{~h}$ reaction.

Additionally, the Pd and $\mathrm{P}$ content for the hybrid catalyst determined after each catalytic run (Table 5) indicates that the $\mathrm{P} / \mathrm{Pd}$ ratio remains stable upon recycling, supporting efficient $\mathrm{Pd}$ redeposition on the support at reaction completion. As no $P$ was detected in solution we exclude detachment of the ligand from the support, despite a slight increase of the $\mathrm{Pd} / \mathrm{P}$ ratio in used catalyst. This explains the differentiated performance between the free C1a-c and $\mathbf{m C 1 a}-\mathbf{c}-\mathrm{TiO}_{2}$ catalysts since the nature of the Pd NPs evolved by the latter is completely different than those evolved by the former, as already suggested by their size histograms.

To gain further insights into the effects of the state surface elemental composition, the XPS patterns for bare $\mathrm{TiO}_{2}, \mathbf{m C 1}-\mathrm{TiO}_{2}$ and $\mathbf{m C 1} \mathbf{c}-\mathrm{TiO}_{2}$ (after $3^{\text {rd }}$ run reused by method $\mathrm{B}$ ) was recorded as shown in Figures S30-S33. Figure S31 shows the XPS signature of the Pd 3d doublet $\left(3 d_{3 / 2}\right.$ and $\left.3 d_{5 / 2}\right)$. According to the observed binding energies, mC1c-TiO 2 (Figure

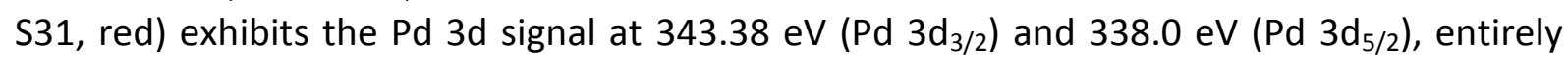
corresponding to $\mathrm{Pd}^{+2}$ whereas $\mathrm{mCl}^{\mathrm{c}}-\mathrm{TiO}_{2}$ after $3^{\text {rd }}$ run reused by method $\mathrm{B}$ (Figure S31, blue) exhibits at $340.6 \mathrm{eV}\left(\mathrm{Pd} 3 \mathrm{~d}_{3 / 2}\right)$ and $335.2 \mathrm{eV}\left(\mathrm{Pd} 3 \mathrm{~d}_{5 / 2}\right)$, corresponding to that of bulk metallic Pd. This confirms that no decomposition of the complex occurs upon grafting and the previously observed nanoparticles are of $\operatorname{Pd}(0)$. Additionally, the phosphorous XPS spectra with signals are attributed to the phosphonate moieties (Figure S32). indicate no change before and after the catalytic test.Interestingly, nitrogen XPS spectra showed that part of the benzimidazole-2-ylidene moieties were oxidized after catalysis (Figure S33).

The optical response of bare $\mathrm{TiO}_{2}, \mathbf{m C 1} \mathbf{c}-\mathrm{TiO}_{2}$ and $\mathbf{m C 1} \mathbf{c}-\mathrm{TiO}_{2}$ (after $3^{\text {rd }}$ run reused by method B) was recorded showing a strong absorption at $<400 \mathrm{~nm}$ in all cases, which is attributed to the intrinsic absorption of $\mathrm{TiO}_{2}$ (Figure S34). However, $\mathbf{m C 1 c}-\mathrm{TiO}_{2}$ (after $3^{\text {rd }}$ run reused by method $\mathrm{B}$ ) exhibited a slightly increase in absorbance in the visible and near infrared region compared to that of $\mathrm{TiO}_{2}$.

In order to unravel the enhanced catalytic activity for $\mathbf{m C l a} \mathbf{c}-\mathrm{TiO}_{2}$, a new series of experiments was performed (Figure 9 and Table 6). 

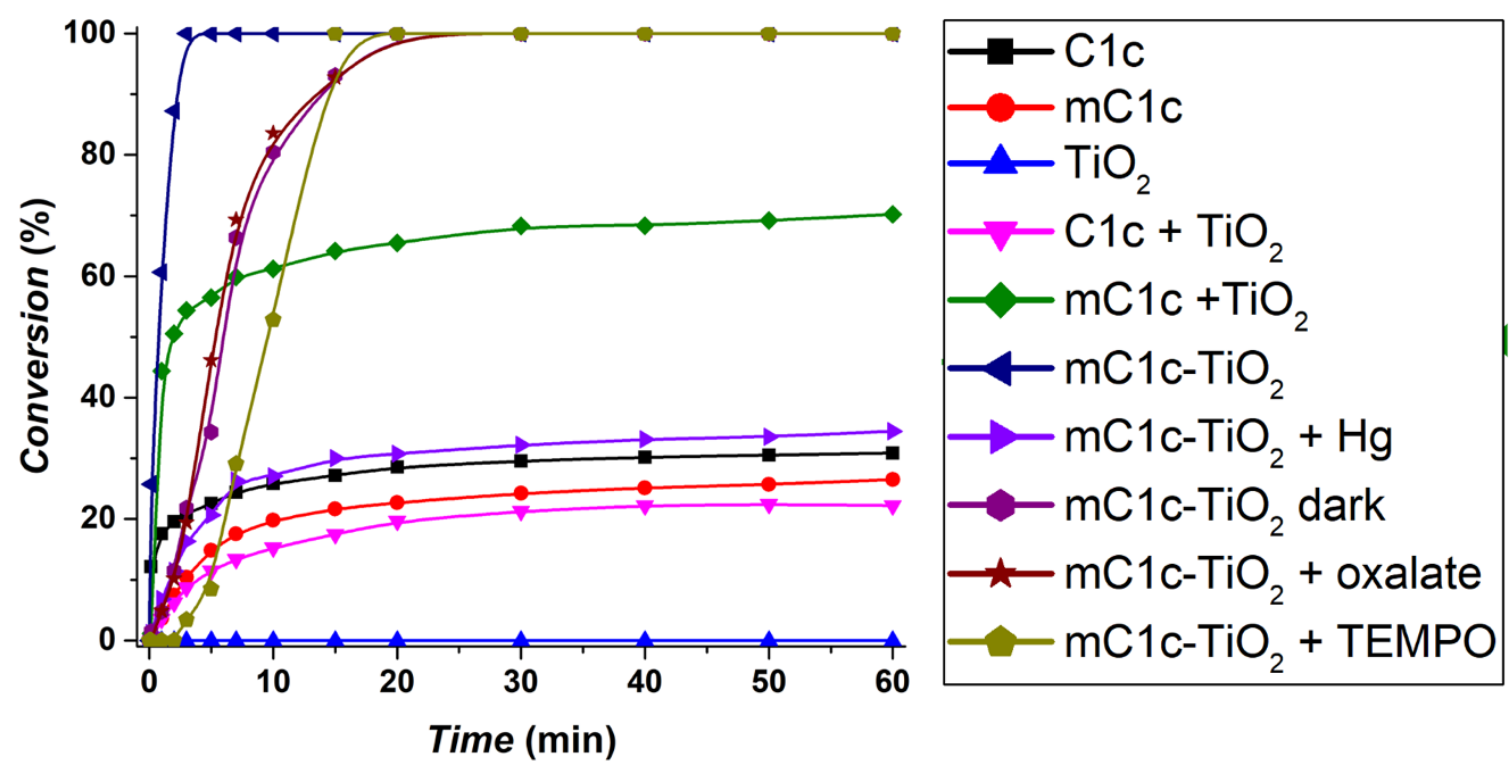

Figure 9. Catalytic performance for the coupling of $p$-bromoacetophenone and phenylboronic acid by using (a) C1c, black, squares, (b) $\mathbf{m C 1}$, red, round, (c) $\mathrm{TiO}_{2}$, blue, triangle, (d) $\mathbf{C 1 c}+\mathrm{TiO}_{2}$, pink, inversed triangle, (e) $\mathbf{m C 1} \mathbf{c}$

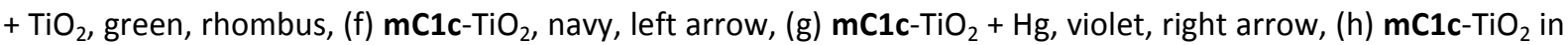
the dark, purple, hexagon, (i) $\mathrm{mCl} \mathbf{c}-\mathrm{TiO}_{2}+$ sodium oxalate, brown, stars, (j) $\mathbf{m C 1}-\mathrm{TiO}{ }_{2}+\mathrm{TEMPO}$, olive, pentagon.

Table 6. Catalyst activities, conversion, TON and TOF values for the Suzuki-Miyaura reaction of $p$ bromoacetophenone and phenylboronic acid.

\begin{tabular}{|c|c|c|c|c|c|c|}
\hline Entry & Catalyst & $\begin{array}{l}\text { iTOF (mol product } \cdot \mathrm{mol} \mathrm{Pd}^{-1} \cdot \mathrm{min}^{-} \\
\text {1) }\end{array}$ & Induction time (min) & Conv. & TON & TOF $\left(h^{-1}\right)$ \\
\hline $1^{8}$ & C1c & 90 & - & 31 & 309 & 927 \\
\hline 2 & $\mathrm{mC} 1 \mathrm{c}$ & 43 & - & 27 & 265 & 530 \\
\hline 3 & $\mathrm{TiO}_{2}$ & - & - & - & - & - \\
\hline 4 & $\mathrm{C} 1 \mathrm{c}+\mathrm{TiO}_{2}$ & 41 & - & 22 & 222 & 444 \\
\hline 5 & $\mathrm{mC} 1 \mathrm{c}+\mathrm{TiO}_{2}$ & 786 & - & 70 & 702 & 1404 \\
\hline 6 & $\mathrm{mC} 1 \mathrm{c}-\mathrm{TiO}_{2}$ & 1914 & - & 100 & 1000 & 20000 \\
\hline 7 & $\mathrm{mC} 1 \mathrm{c}-\mathrm{TiO}_{2}+\mathrm{Hg}$ & 68 & - & 35 & 345 & 690 \\
\hline 8 & $\mathrm{mC} 1 \mathrm{c}-\mathrm{TiO}_{2}$ in the dark & 498 & - & 100 & 1000 & 3000 \\
\hline 9 & $\mathrm{mC} 1 \mathrm{c}-\mathrm{TiO}_{2}+$ oxalate & 421 & - & 100 & 1000 & 3000 \\
\hline 10 & $\mathrm{mC} 1 \mathrm{c}-\mathrm{TiO}_{2}+\mathrm{TEMPO}$ & 352 & 2 & 100 & 1000 & 4000 \\
\hline
\end{tabular}

Reaction conditions: $8 \times 10^{-4} \mathrm{mmol} \mathrm{Pd}, 0.8 \mathrm{mmol}$ p-bromoacetophenone, $1 \mathrm{mmol}$ phenylboronic acid and $1.2 \mathrm{mmol} \mathrm{MeONa}$ in $16 \mathrm{~mL}$ absolute EtOH. Conversion after $1 \mathrm{~h}$ reaction.

First, the non-grafted $\mathbf{m C 1}$ complex (containing the phosphonate groups) was tested (Figure 9, red, round) exhibiting a similar performance to that of C1c (Figure 9, black, squares). However, two times lower iTOF was observed for this catalyst (Table 6, entry 2 ). This is attributed to steric hindrance due to the bulky ethyl phosphonate moieties. 


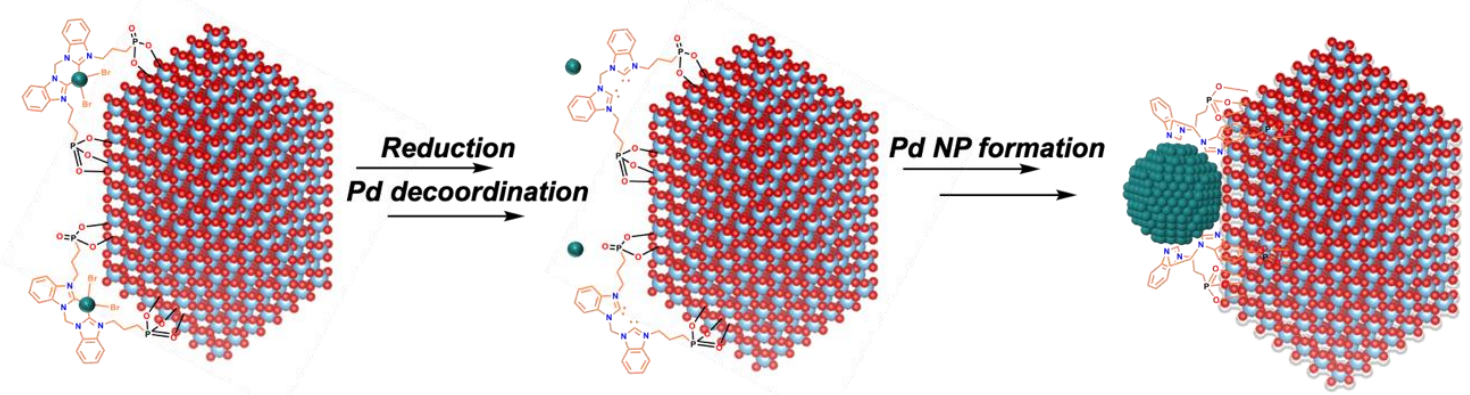

Scheme 3. Catalyst evolution of grafted Pd-bisNHC complexes at the surface of $\mathrm{TiO}_{2}$.

Second, the role of the $\mathrm{TiO}_{2}$ support was also studied. While no reactivity was observed with $\mathrm{TiO}_{2}$ alone, $\mathrm{TiO}_{2}$ in the presence of $\mathrm{Clc}$ (Figure 9, pink, inversed triangle) gave a lower performance than that of single C1c. Interestingly, Pd NPs evolved under these conditions were not deposited at the surface of $\mathrm{TiO}_{2}$ (Figure S29). Thus, the formation of Pd NPs at the surface of $\mathrm{TiO}_{2}$ could be ascribed to their stabilization by the grafted ligands (Scheme 3). To confirm this hypothesis, the 3a ligand (see Scheme 1) was grafted at the surface of $\mathrm{TiO}_{2}$, yielding the $3 \mathrm{a}-\mathrm{TiO}_{2}$ material (Figures S35-S36, sand Experimental section), which was introduced in the standard catalytic test in the co-presence of the C1c complex (see Experimental section). As shown in Figure 10a, no depletion of the C1c catalyst was observed in the presence of the $3 \mathrm{a}-\mathrm{TiO}_{2}$ material, achieving a complete conversion after $40 \mathrm{~min}$. Additionally, the TEM image of $3 \mathrm{a}-\mathrm{TiO}_{2}$ after performing the reaction (Figure 10b) reveals the formation of $\mathrm{Pd}$ NPs of $1.4 \pm 0.3 \mathrm{~nm}$ at the surface of $\mathrm{TiO}_{2}$. This confirms the above hypothesis that ligand must be grafted onto $\mathrm{TiO}_{2}$ to form $\mathrm{Pd} \mathrm{NPs}$ at the $\mathrm{TiO}_{2}$ surface. Also, ICP-OES analysis for the isolated hybrid catalyst provided a $0.14 \% \mathrm{Pd}$ content. Additionally, the resulting $\mathrm{Pd}$-enriched hybrid catalyst was further reused exhibiting a lower catalytic performance with ca. 15\% conversion as shown in Figure S37. This phenomenon is attributed to a screen effect by the Pd NPs covering $\mathrm{TiO}_{2}$. 
a)

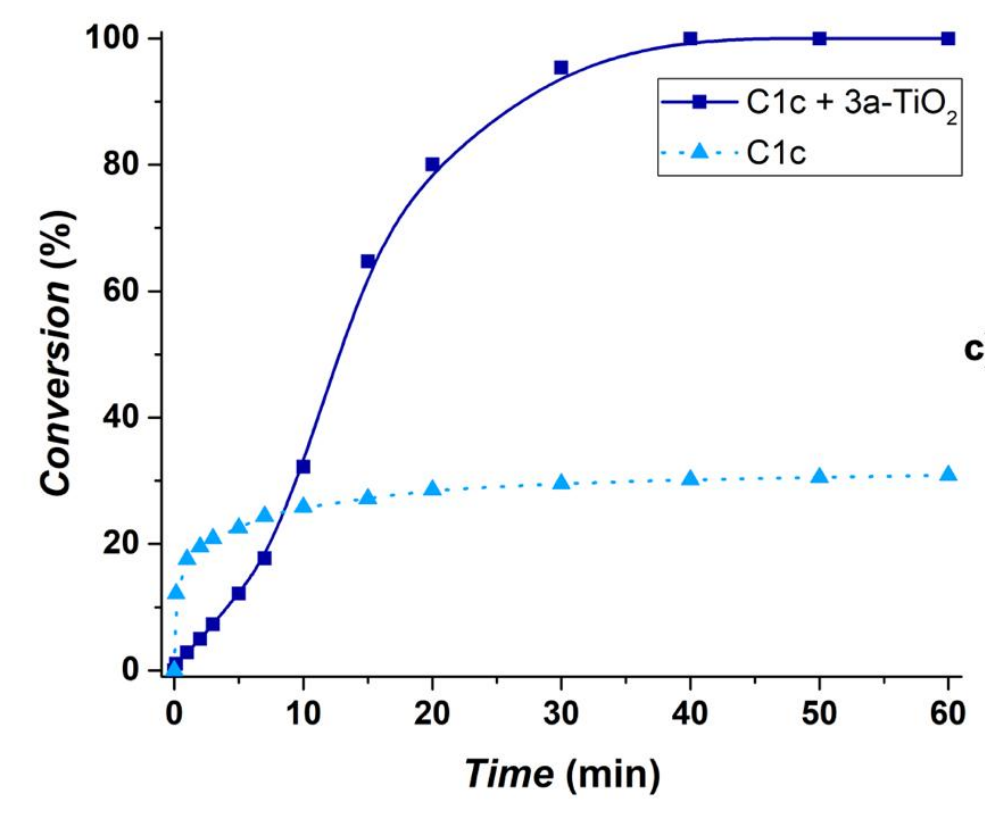

b)

c)
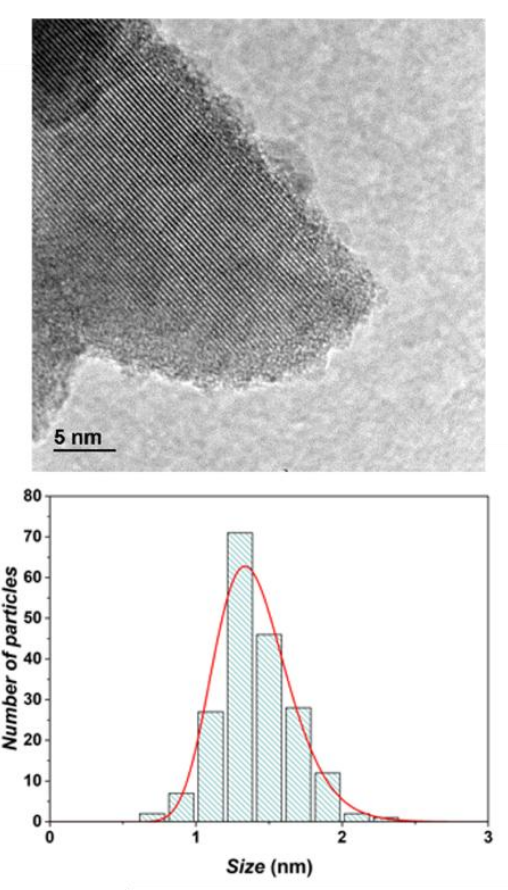

Figure 10. (a) Comparison of the catalytic activities for the C1c catalyst in the absence and in the presence of the $3 \mathrm{a}-\mathrm{TiO}_{2}$ material for the $\mathrm{C}-\mathrm{C}$ coupling of $p$-bromoacetophenone and phenylboronic acid. Reaction conditions: $8 \times 10^{-4} \mathrm{mmol} \mathrm{Pd}, 0.8 \mathrm{mmol} p$-bromoacetophenone, $1 \mathrm{mmol}$ phenylboronic acid, $1.2 \mathrm{mmol} \mathrm{MeONa}$, $16 \mathrm{~mL} \mathrm{EtOH}, 60^{\circ} \mathrm{C}$. (b) TEM micrograph of the $3 \mathrm{a}-\mathrm{TiO}_{2}$ material with (c) its size histogram after the catalytic reaction.

On the other hand, when the free $\mathbf{m C l c}$ complex was tested in the presence of $\mathrm{TiO}_{2}$ (Figure 9 , green, rhombus), a medium overall performance with an iTOF of $43 \mathrm{~min}^{-1}$ was observed probably due to (partial) in situ grafting of the complex.

Third, to elucidate the nature of the active species two separate $\mathrm{Hg}$ poisoning tests were performed. A large excess of $\mathrm{Hg}(0)(\mathrm{Hg}: \mathrm{Pd} \approx 2000: 1 \mathrm{~mol} / \mathrm{mol})$ was added to the reaction mixture at the beginning for $\mathrm{mClc}^{-1} \mathrm{TiO}_{2}$ at $60^{\circ} \mathrm{C}$ (Figure 9, violet, right arrow). Then, the iTOF dramatically decreased to $68 \mathrm{~min}^{-1}$ (Table 6 , entry 7). In the other experiment, when $\mathrm{Hg}(0)$ was added after $15 \mathrm{~min}$ of reaction at $25^{\circ} \mathrm{C}$, the conversion ceased completely (Figure 11). These data also suggest that the grafted $\mathbf{m C 1 c}$ complex acts in fact as pre-catalyst and its evolved Pd NPs are the active species or reservoirs of them. 


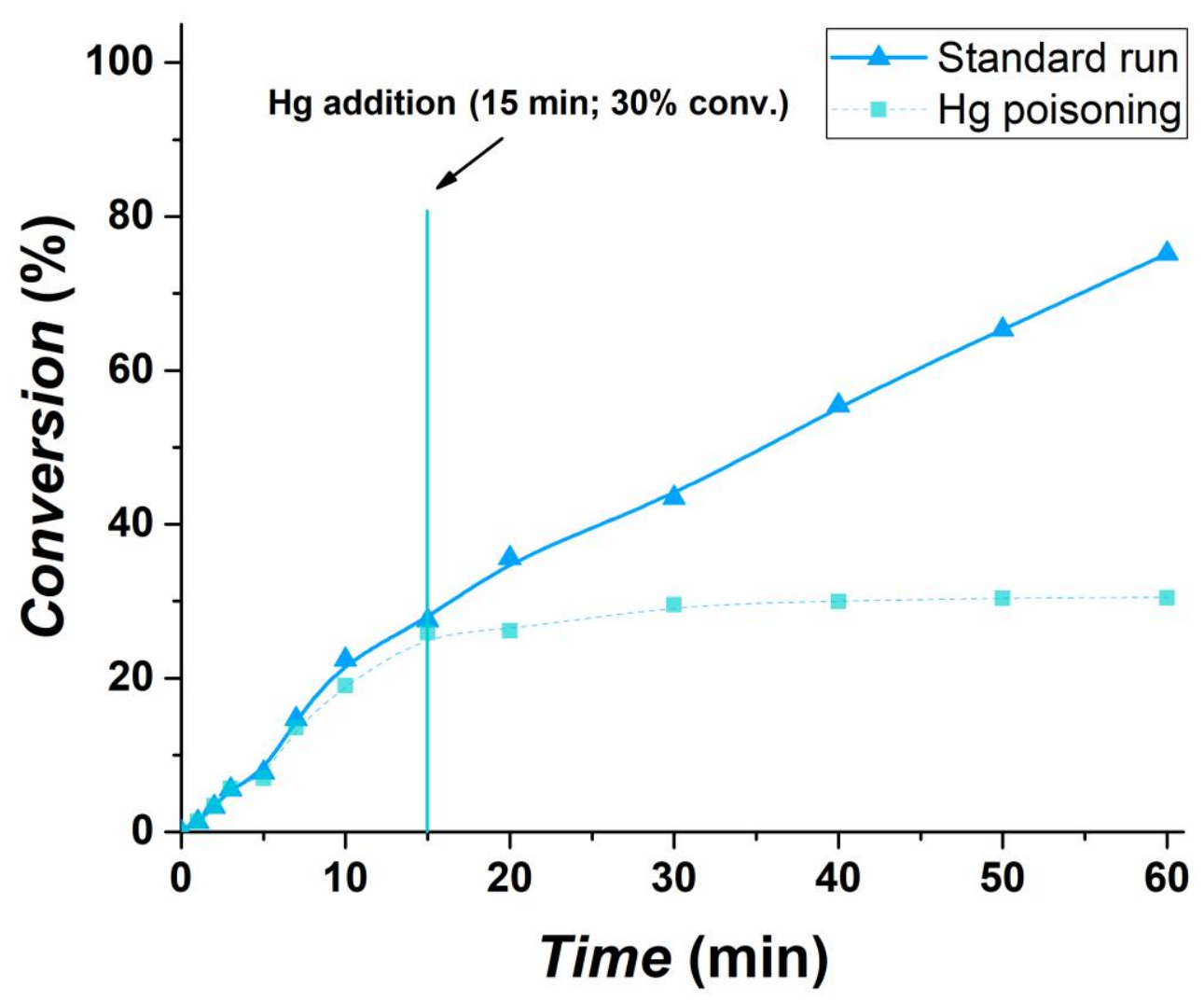

Figure 11. Comparison of the catalytic activities for $\mathbf{m C 1}-\mathrm{TiO}_{2}$ catalyst in the absence (standard run) and after the addition of $\mathrm{Hg}$ ( $\mathrm{Hg}$ poisoning) for the coupling of $\mathrm{p}$-bromoacetophenone and phenylboronic acid at $25^{\circ} \mathrm{C}$.

Fourth, since the $\mathrm{TiO}_{2} \mathrm{P}-25$ support possesses semiconductor properties, we evaluated the possibility of photocatalytic assistance. For that, three different experiments were conducted. On the one hand, the $\mathbf{m C 1 c}^{-\mathrm{TiO}_{2}}$ performance was studied in the dark (Figure 9, purple, hexagon) revealing a lower iTOF (Table 6, entry 8 ) but a complete conversion in the first 20 min. Interestingly, when $\mathrm{mCl}^{\mathrm{C}}-\mathrm{TiO}_{2}$ was tested as usual but in the presence of a hole scavenger (sodium oxalate) ${ }^{30}$ (Figure 9, brown, stars and Table 6, entry 9), the same reactivity was observed as that in the dark. Since $\mathrm{Ph}-\mathrm{B}(\mathrm{OH})_{2}$ can react in basic medium to form negative $\mathrm{Ph}-\mathrm{B}(\mathrm{OH})_{3}{ }^{-}$species, the holes $\mathrm{h}^{+}$can assist in cleaving the $\mathrm{C}-\mathrm{B}$ bond to produce biaryl-Pd species. Moreover, ${ }^{11} \mathrm{~B}$ solid-state NMR experiments were recorded for $\mathrm{Ph}-\mathrm{B}(\mathrm{OH})_{2}$ (Figure 12, black line), $\mathrm{Ph}-\mathrm{B}(\mathrm{OH})_{2}$ after $1 \mathrm{~h}$ reacting with 1.25 equivalents of $\mathrm{MeONa}$ in $\mathrm{EtOH}$ (Figure 12, red line) and $\mathrm{Ph}-\mathrm{B}(\mathrm{OH})_{2}$ acid after $1 \mathrm{~h}$ reacting with 1.25 equivalents of $\mathrm{MeONa}$ in the presence of 1 equivalent of $\mathrm{TiO}_{2}$ in $\mathrm{EtOH}$ (Figure 12, blue line). The $\mathrm{Ph}-\mathrm{B}(\mathrm{OH})_{2}+\mathrm{OH}^{-} \rightleftharpoons$ $\mathrm{Ph}-\mathrm{B}(\mathrm{OH})_{3}{ }^{-}$equilibrium, which presents the 55:45 ratio, was shifted to the right after the introduction of $\mathrm{TiO}_{2}$ revealing a 36:64 ratio. Thus, these three experiments indicate that the photogenerated $\mathrm{h}^{+}$in $\mathrm{TiO}_{2}$ contribute to the $\mathrm{Ph}-\mathrm{B}(\mathrm{OH})_{2}-\mathrm{TiO}_{2}$ surface interaction accelerating the trans-metalation step. ${ }^{31}$ On the other hand, when $\mathbf{m C 1} \mathbf{c}-\mathrm{TiO}_{2}$ was tested in the presence of an electron scavenger such as TEMPO (Figure 9, olive, pentagon), a quasi shift relative to mC1c- $\mathrm{TiO}_{2}$ was observed prompting to hypothesize that the photogenerated electrons accelerate the oxidative addition step. 


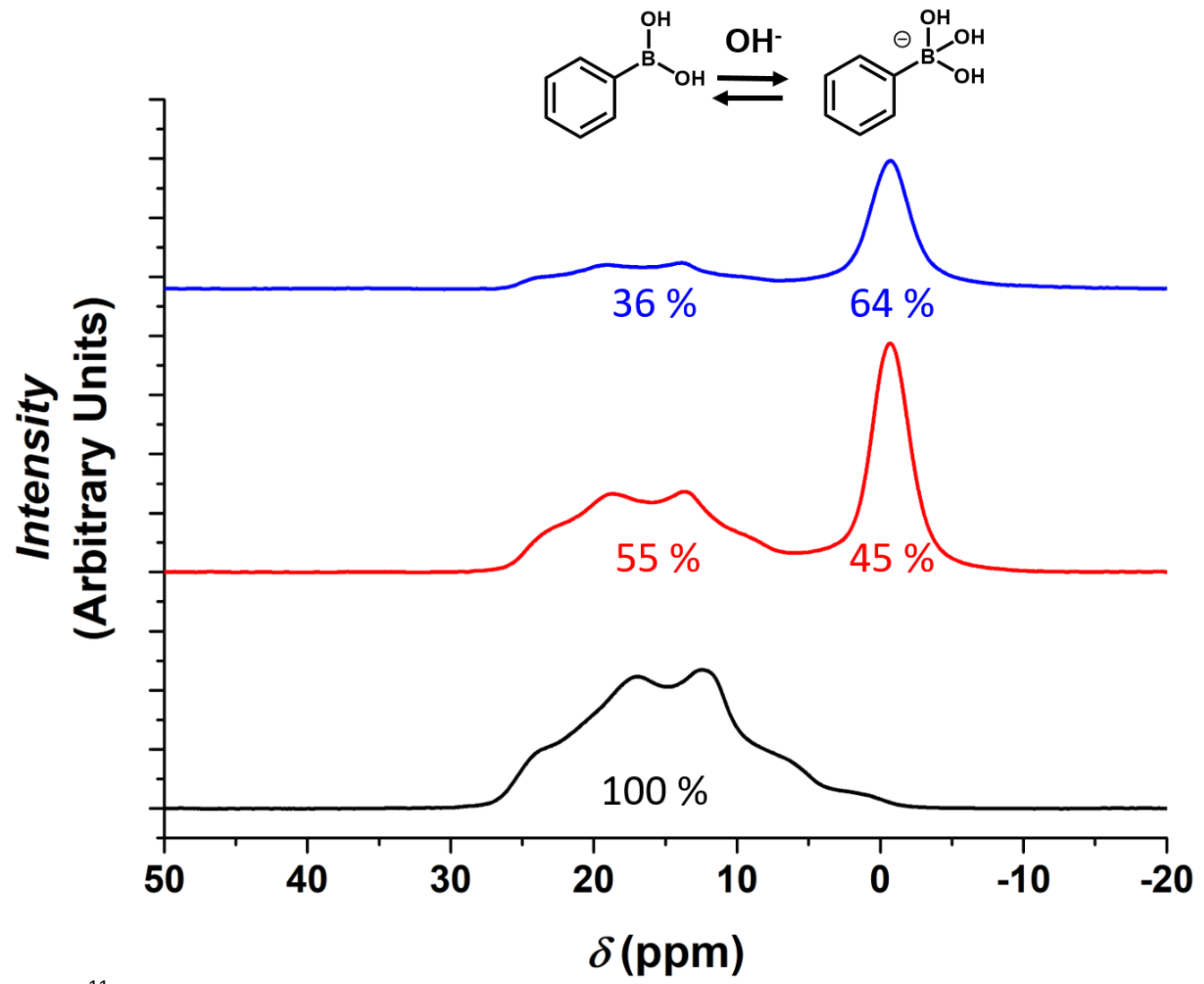

Figure 12. ${ }^{11} \mathrm{~B}$ MAS NMR spectrum for the phenylboronic acid (black line), phenylboronic acid after $1 \mathrm{~h}$ reaction with 1.25 equivalents of $\mathrm{MeONa}$ in $\mathrm{EtOH}$ (red line) and phenylboronic acid after $1 \mathrm{~h}$ reaction with 1.25 equivalents of $\mathrm{MeONa}$ in the presence of 1 equivalent of $\mathrm{TiO}_{2}$ in $\mathrm{EtOH}$ (blue line).

Since the work function of palladium is located between the $\mathrm{HOMO}$ and $\mathrm{LUMO}$ of $\mathrm{TiO}_{2}\left(\Phi_{\mathrm{Pd}}>\right.$ $\left.\Phi_{\mathrm{TiO} 2}\right)$, the formation of Pd NPs at the surface of $\mathrm{TiO}_{2}$ results in the in situ generation of a rectifying metal-semiconductor contact, a Mott-Schottky heterojunction ${ }^{32}$ as shown in Scheme 4. Thus, a charge transfer at the interface occurs resulting in a positively charged region in $\mathrm{TiO}_{2}$ and negatively charged Pd NPs due to the Schottky effect. The energetic $\mathrm{e}^{-}$ located at the Pd NPs and $\mathrm{h}^{+}$located at the $\mathrm{TiO}_{2}$ surface can contribute to activate the $p$ bromoacetophenone and phenylboronic acid, respectively. Consequently, the SuzukiMiyaura reaction is accelerated. However, this heterojunction can only be formed thanks to the proximity of the Pd atoms by the grafted complexes, which could be attributed to both the contribution to the $\mathrm{Pd}(\mathrm{II}) \rightarrow \mathrm{Pd}(0)$ reduction by the photogenerated electrons in $\mathrm{TiO}_{2}$ and the stabilization by the grafted ligands.

On the basis of the obtained results, we propose a mechanism (Scheme 4) in which the phenomena above mentioned take place. 


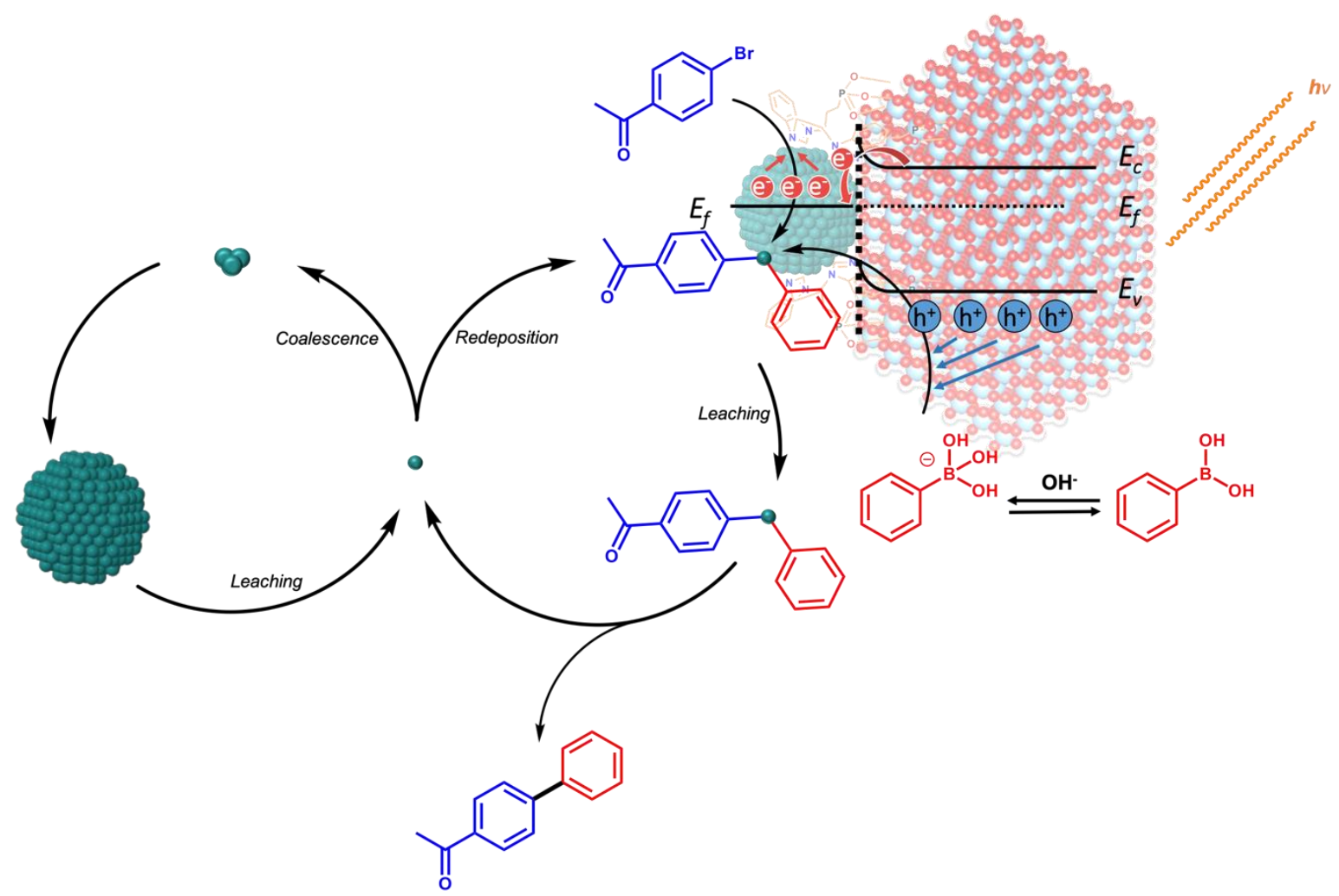

Scheme 4. Catalyst evolution and Mott-Schottky heterojunction photocatalytic contribution showing the view of the rectifying metal-semiconductor $\left(\mathrm{TiO}_{2}\right)$ contact. Legend: $\mathrm{E}_{\mathrm{v}}$, Valence band $(\mathrm{HOMO}) ; \mathrm{E}_{\mathrm{c}}$, Conduction band (LUMO); $E_{f}$, work function.

\subsection{Scope of the Suzuki-Miyaura reaction}

Following these mechanistic studies, a reaction scope for the Suzuki-Miyaura reaction was evaluated for different aryl bromides by using $\mathbf{m C 1 c}^{-\mathrm{TiO}_{2}}$ to form more functionalized products (Figure 13). As usually observed for such coupling, aryl bromides with electronwithdrawing substituents were particularly reactive giving high yields (4a-4g). Aryl bromides bearing electron-donating substituents resulted in moderate yields (4h-4o). However, $\mathbf{4 p}$ could not be obtained due to its reactivity under basic condition towards its enolate form, which can evolve to a quinone derivative. ${ }^{33}$ Also, bulky aromatics provided mainly quantitative yields (4q-4t). Heteroaromatics bromides were also evaluated giving in general moderate to quantitative yields for pyridyl, quinolines and isoquinolines (4u-4y) but $8 \%$ and $0 \%$ yield for $\mathbf{4 v}$ and $\mathbf{4 x}$, respectively. However, the catalyst could not activate (benz)imidazolium bromides (4z-4ab), sulfur-containing heteroaromatics bromides (4ac4ae), oxygen-containing heteroaromatics bromides (4af-4ag) and indole bromide (4ah-4al) but 4ak with a moderate product yield in these conditions without substrate optimization. 


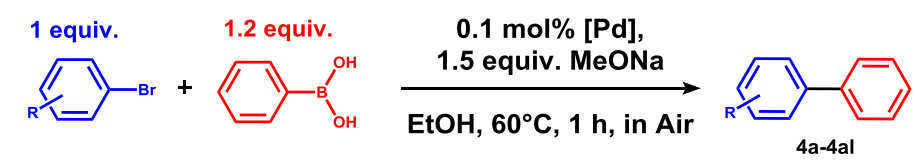

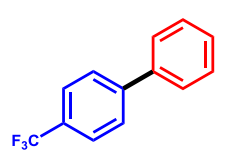

4a (99\%)<smiles>Clc1ccccc1-c1ccccc1</smiles>

4 ( $(89 \%)$<smiles>COc1ccc(-c2ccccc2)cc1</smiles>

4k $(67 \%)$<smiles>Oc1ccc(-c2ccccc2)cc1</smiles>

$4 p(0 \%)$<smiles>c1ccc(-c2ccccn2)cc1</smiles>

4u $(99 \%)$<smiles>c1ccc(-c2c[nH]cn2)cc1</smiles>

$4 z(0 \%)$<smiles>c1ccc(-c2ccc3sccc3c2)cc1</smiles>

4ae $(0 \%)$<smiles>c1ccc(-c2ccc3cc[nH]c3c2)cc1</smiles>

4aj $(0 \%)$<smiles>FC(F)(F)c1cccc(-c2ccccc2)c1</smiles>

4b $(99 \%)$

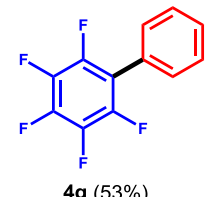<smiles>COc1cc(OC)cc(-c2ccccc2)c1</smiles>

4 I (36\%)<smiles>c1ccc(-c2cccc3ccccc23)cc1</smiles>

4q (99\%)<smiles>c1ccc(-c2cccc(-c3ccccn3)c2)cc1</smiles>

4 v $(8 \%)$

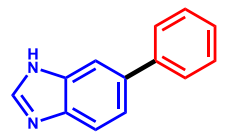

4aa $(0 \%)$

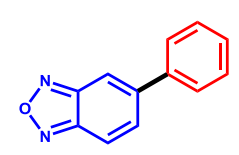

4af $(0 \%)$<smiles>c1ccc(-c2ccc3[nH]ccc3c2)cc1</smiles>

4ak (56\%)<smiles>Cc1ccc(-c2ccccc2)cc1</smiles>

4c $(99 \%)$<smiles>c1ccc(-c2ccccc2)cc1</smiles>

4h $(71 \%)$<smiles>COc1ccc(-c2ccccc2)cc1OC</smiles>

$4 \mathrm{~m}(52 \%)$<smiles>c1ccc(-c2ccc3ccc4cccc5ccc2c3c45)cc1</smiles>

4r $(96 \%)$<smiles>c1ccc(-c2cnc3ccccc3c2)cc1</smiles>

4w $(99 \%)$

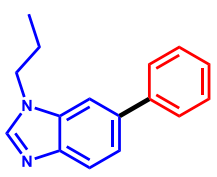

4ab $(0 \%)$<smiles>c1ccc(-c2ccoc2)cc1</smiles>

4ag $(0 \%)$<smiles>c1ccc(-c2cccc3cc[nH]c23)cc1</smiles>

4al (3\%)<smiles>N#Cc1ccc(-c2ccccc2)cc1F</smiles>

4d $(81 \%)$

4e $(99 \%)$<smiles>COc1ccccc1-c1ccccc1</smiles>

$4 i(36 \%)$<smiles>COc1cccc(-c2ccccc2)c1</smiles>

4j (59\%)<smiles>Cc1ccc(-c2ccccc2)cc1</smiles>

4n (68\%)<smiles>Oc1ccccc1-c1ccccc1</smiles>

$40(36 \%)$<smiles>c1ccc(-c2ccc3ccccc3c2)cc1</smiles>

4s $(94 \%)$

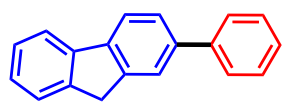

4t $(80 \%)$<smiles>c1ccc(-c2cccc3cccnc23)cc1</smiles>

$4 \times(0 \%)$<smiles>c1ccc(-c2cncc3ccccc23)cc1</smiles>

4y $(68 \%)$

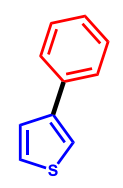

4ac $(0 \%)$<smiles>c1ccc(-c2csc3ccccc23)cc1</smiles>

4ad $(0 \%)$

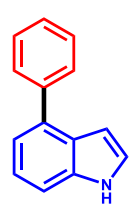

4ai $(0 \%)$

Figure 13. Reaction scope for the coupling of aryl bromides with phenylboronic acid in the presence of the mC1c- $\mathrm{TiO}_{2}$ catalyst. 


\section{Conclusions}

We have prepared and characterized a new series of NHC-based Pd(II) complexes, which have been immobilized at the surface of $\mathrm{TiO}_{2}$. These new hybrid materials were used as heterogeneous catalysts for the Suzuki-Miyaura reaction with the aim of providing new insights into the nature of active species in such catalysts.

First, all transformations gave quantitative yields for the coupling of $p$-bromoacetophenone and phenylboronic acid at $60^{\circ} \mathrm{C}$, and moderate to excellent yields at $25^{\circ} \mathrm{C}$. Moreover, the TOF values reached up to $20000 \mathrm{~h}^{-1}$ at $0.1 \%$ catalyst loading under environmentally friendly mild conditions.

Then, we have demonstrated that the heterogenized complexes not only exhibit better performances than for the corresponding homogeneous counterparts but also imply a different mechanism. Following the catalytic and recyclability studies, mercury poisoning tests, TEM and ${ }^{31}$ P HPDEC NMR analyses we propose that the enhanced catalytic activities can be ascribed to the leaching of highly-active Pd species from the evolved Pd NPs at the surface of $\mathrm{TiO}_{2}$. Interestingly for the $\mathbf{m C 1 c}-\mathrm{TiO}_{2}$ catalyst, we evidenced that the $\mathrm{TiO}_{2}$ nanostructure not only serves as support but also as photoinduced boosting tool due to the in situ generation of Mott-Schottky heterojunctions. Thus, the photogenerated electrons in $\mathrm{TiO}_{2}$ transferred to the Pd NPs facilitate the cleavage of the $\mathrm{C}-\mathrm{Br}$ in aryl halides, while the photogenerated holes assist the cleavage of the C-B bond in the phenylboronic acid. A possible mechanism of the chemical transformation of the hybrid catalysts, the enhancing effect by $\mathrm{TiO}_{2}$ and the leaching of $\mathrm{Pd}$ species is therefore proposed here pointing that the evolved Pd NPs act as reservoirs of highly-active Pd species.

Finally, after revealing the applicability of $\mathbf{m C 1 c}^{-\mathrm{TiO}_{2}}$ upon recycling, a scope of substrates exhibited moderate to excellent yields for (de)activated aryl bromides as well as for sterically hindered and heteroaromatic derivatives.

\section{Experimental}

\subsection{Materials and methods}

Evonik/Degussa AEROXIDE ${ }^{\circledR} \mathrm{TiO}_{2} \mathrm{P}-25$ powder formed of nanoparticles of $21 \mathrm{~nm}$ average size was sourced from Nippon Aerosil (Yokkaichi, Japan). The rest of reagents were acquired from Sigma-Aldrich and Alfa Aesar.

All analyses were performed at IRCELYON except notified.

GC analyses were performed on a Shimadzu GC-2030 gas chromatograph equipped with a FID detector, a HP-5 column (cross-linked 5\% phenylmethylsiloxane, $30 \mathrm{~m} \times 0.25 \mathrm{~mm} \times 0.25$ $\mu \mathrm{m}$ ) with helium as carrier gas. Yields were determined by GC based on the relative area of GC signals referred to an internal standard (naphthalene) calibrated to the corresponding pure compounds. 
${ }^{1} \mathrm{H}$ NMR, ${ }^{13} \mathrm{C}$ NMR, ${ }^{31} \mathrm{P}\left\{{ }^{1} \mathrm{H}\right\}$ NMR, HSQC and HMBC spectra were recorded on an AVANCE III 400 Bruker spectrometer at a temperature of $25^{\circ} \mathrm{C}$. All chemical shifts were given in ppm.

${ }^{31} \mathrm{P}$ solid-state NMR spectra for hybrid materials were recorded on an AVANCE III 500WB Bruker spectrometer with the high-power decoupling (HPDEC) technique. ${ }^{13} \mathrm{C}$ solid-state NMR spectra for hybrid materials were recorded on an AVANCE III 500WB Bruker spectrometer with the cross-polarization magic angle spinning (CP-MAS) technique. ${ }^{11} B$ solid-state NMR spectra for hybrid materials were recorded on an AVANCE III 500WB Bruker spectrometer with the magic angle spinning (MAS) technique.

The palladium content was determined on an ICP-OES ACTIVA Jobin Yvon apparatus from solutions obtained by treatment of the catalysts with sulfuric acid and aqua regia in a Teflon reactor at $400-450^{\circ} \mathrm{C}$.

Electrospray ionization Mass Spectrometry (ESI-MS) experiments were performed on a QTOF Impact II Bruker instrument equipped with an UHPLC U3000 Dionex system by the Centre Commun de Spectrométrie de Masse at the University of Lyon 1.

Transmission electron microscopy (TEM) analyses were carried out on a JEOL 2010 microscope with an instrumental magnification of 50000x to 100000x and an acceleration voltage of $200 \mathrm{kV}$. The point-to-point resolution of the microscope was $0.19 \mathrm{~nm}$ and the resolution between the lines was $0.14 \mathrm{~nm}$. The size distributions were determined via manual analysis of enlarged images by measuring ca. 200 particles on a given grid to obtain a statistical size distribution and a mean diameter.

Infrared (IR) spectra were recorded with a Thermo Scientific Nicolet iS5 spectrometer in the $4000-525 \mathrm{~cm}^{-1}$ range in attenuated total reflectance (ATR) mode.

X-ray photoelectron spectroscopy (XPS) analyses were carried out with a Versa Probe II spectrometer (ULVAC-PHI) equipped with a monochromated Al K $\alpha$ source (hv = $1486.6 \mathrm{eV}$ ) at CEA Grenoble-. The core level peaks were recorded with constant pass energy of $23.3 \mathrm{eV}$. The XPS spectra were fitted with CasaXPS 2.3 software using Shirley background. Binding energies are referenced with respect to the adventitious carbon ( $C 1 \mathrm{~s} \mathrm{BE}=284.6 \mathrm{eV}$ ).

UV-Vis absorption spectra were carried out with a LAMBDA 365 UV/VIS Spectrophotometer from Pelkin Elmer (Walmar, MA, USA) in solid-state at room temperature.

\subsection{Synthesis and characterization of the ligands}

4.2.1 1, 1 '-methylenebisbenzimidazole $(2 \boldsymbol{a})$. A DMSO $(10 \mathrm{~mL})$ solution of benzimidazole (2929 mg, $24.8 \mathrm{mmol}, 2 \mathrm{eq}$ ) and potassium hydroxide (5563 mg, $99.2 \mathrm{mmol}, 8 \mathrm{eq}$ ) was stirred at room temperature for $1 \mathrm{~h}$. Then, diiodomethane $(1 \mathrm{~mL}, 12.4 \mathrm{mmol}, 1 \mathrm{eq})$ was added at once and the reaction was stirred overnight. After the addition of water $(150 \mathrm{~mL})$, the product was extracted with dichloromethane $(3 \times 10 \mathrm{~mL})$, dried over magnesium sulfate and concentrated. Diethyl ether $(50 \mathrm{~mL})$ was added to precipitate a white powder. Yield: 2470 $\mathrm{mg}, 80 \%$. The spectroscopic data matched that reported in the literature. ${ }^{14}$

4.2.2 1,1'-(dimethylene)bisbenzimidazole $(\mathbf{2 b})$. A DMSO $(10 \mathrm{~mL})$ solution of benzimidazole (1000 mg, $8.46 \mathrm{mmol}, 2 \mathrm{eq}$ ) and potassium hydroxide $(475 \mathrm{mg}, 8.46 \mathrm{mmol}, 2 \mathrm{eq}$ ) was stirred 
at room temperature for $1 \mathrm{~h}$. Then, dibromoethane $(0.37 \mathrm{~mL}, 4.23 \mathrm{mmol}, 1 \mathrm{eq})$ was added at once and the reaction was stirred overnight. After the addition of water $(150 \mathrm{~mL})$, the product was extracted with dichloromethane $(3 \times 10 \mathrm{~mL})$, dried over magnesium sulfate and concentrated. Diethyl ether $(50 \mathrm{~mL})$ was added to precipitate a white powder. Yield: $154 \mathrm{mg}$, $14 \%$. The spectroscopic data matched that reported in the literature. ${ }^{14}$

4.2.3 1,1'-(trimethylene)bisbenzimidazole $(2 c)$. A DMSO $(10 \mathrm{~mL})$ solution of benzimidazole (1000 mg, $8.46 \mathrm{mmol}, 2 \mathrm{eq}$ ) and potassium hydroxide $(475 \mathrm{mg}, 8.46 \mathrm{mmol}, 2 \mathrm{eq}$ ) was stirred at room temperature for $1 \mathrm{~h}$. Then, diiodopropane $(0.43 \mathrm{~mL}, 4.23 \mathrm{mmol}, 1 \mathrm{eq})$ was added at once and the reaction was stirred overnight. After the addition of water $(150 \mathrm{~mL})$, the product was extracted with dichloromethane $(3 \times 10 \mathrm{~mL})$, dried over magnesium sulfate and concentrated. Diethyl ether $(50 \mathrm{~mL})$ was added to precipitate a white powder. Yield: $494 \mathrm{mg}$, $42 \%$. The spectroscopic data matched that reported in the literature. ${ }^{14}$

\subsubsection{1,1'-Di(3-diethoxyphosphoryl)propyl-3,3'-methylenebisbenzimidazolium dibromide}

(3a). A mixture of diethyl (3-bromopropyl)phosphonate (387 $\mu \mathrm{L}, 2 \mathrm{mmol}, 2 \mathrm{eq}$ ) and 2a (250 $\mathrm{mg}, 1 \mathrm{mmol}, 1 \mathrm{eq}$ ) was stirred at $80^{\circ} \mathrm{C}$ for 24 hours. After cooling to room temperature, the crude was solved in dichloromethane $(3 \mathrm{~mL})$ and diethyl ether $(25 \mathrm{~mL})$ was added to precipitate a white off hygroscopic solid. Yield: $760 \mathrm{mg}, 99 \% .{ }^{1} \mathrm{H} \mathrm{NMR}\left(\mathrm{CDCl}_{3}, 25^{\circ} \mathrm{C}\right): \delta 1.25(\mathrm{t}$, $\left.J=6.97 \mathrm{~Hz}, 12 \mathrm{H}, \mathrm{H}_{12}\right), 1.93\left(\mathrm{~m}, 4 \mathrm{H}, \mathrm{H}_{10}\right), 2.38\left(\mathrm{~m}, 4 \mathrm{H}, \mathrm{H}_{9}\right), 4.03\left(\mathrm{~m}, 8 \mathrm{H}, \mathrm{H}_{11}\right), 4.77(\mathrm{t}, J=7.46$ $\left.\mathrm{Hz}, 4 \mathrm{H}, \mathrm{H}_{8}\right), 7.55\left(\mathrm{t}, J=7.96 \mathrm{~Hz}, 2 \mathrm{H}, \mathrm{H}_{3}\right), 7.65\left(\mathrm{t}, J=7.83 \mathrm{~Hz}, 2 \mathrm{H}, \mathrm{H}_{6}\right), 7.86(\mathrm{~d}, J=8.40 \mathrm{~Hz}, 2 \mathrm{H}$, $\left.\mathrm{H}_{5}\right), 8.16\left(\mathrm{~s}, 2 \mathrm{H}, \mathrm{H}_{13}\right), 8.74\left(\mathrm{~d}, J=8.63 \mathrm{~Hz}, 2 \mathrm{H}, \mathrm{H}_{4}\right), 11.32\left(\mathrm{~s}, 2 \mathrm{H}, \mathrm{H}_{1}\right) .{ }^{31} \mathrm{P} \mathrm{NMR}\left(\mathrm{CDCl}_{3}, 25^{\circ} \mathrm{C}\right): \delta$ 30.17. ${ }^{13} \mathrm{C} \mathrm{NMR}\left(\mathrm{CDCl}_{3}, 25^{\circ} \mathrm{C}\right): \delta 16.5\left(\mathrm{~d}, J=5.83 \mathrm{~Hz}, \mathrm{C}_{12}\right), 22.2\left(\mathrm{~d}, J=141.87 \mathrm{~Hz}, \mathrm{C}_{10}\right), 22.6(\mathrm{~d}, J$ $\left.=5.00 \mathrm{~Hz}, \mathrm{C}_{9}\right), 47.8\left(\mathrm{~d}, J=12.56 \mathrm{~Hz}, \mathrm{C}_{8}\right), 56.5\left(\mathrm{C}_{13}\right), 62.2\left(\mathrm{~d}, J=6.55 \mathrm{~Hz}, \mathrm{C}_{11}\right), 113.6\left(\mathrm{C}_{5}\right), 114.8$ $\left(C_{4}\right), 127.7\left(C_{3}\right), 128.4\left(C_{6}\right), 130.8\left(C_{2}\right), 131.2\left(C_{7}\right), 144.4\left(C_{1}\right)$. IR (ATR) cm ${ }^{-1}: 2978 v(C-H) a r$, $2931 v(\mathrm{C}-\mathrm{H}), 1397(\delta(\mathrm{C}=\mathrm{C}), \delta(\mathrm{C}=\mathrm{N}))$ ar, $1215(\mathrm{P}=\mathrm{O})$ st, 1014 (P-O-C)st, $758 \delta(\mathrm{C}-\mathrm{H})$ oop. HR-ESIMS (DMSO): calculated: $m / z=687.1899\left([\mathrm{M}+\mathrm{Na}]^{+}\right)$; found: $m / z=687.1895\left([\mathrm{M}+\mathrm{Na}]^{+}\right)$, $303.1362\left([\mathrm{M}-2 \mathrm{Br}]^{+2}\right)$.

\subsubsection{1,1'-Di(3-diethoxyphosphoryl)propyl-3,3'-(dimethylene)bisbenzimidazolium} dibromide (3b). A mixture of diethyl (3-bromopropyl)phosphonate (147 $\mu \mathrm{L}, 0.76 \mathrm{mmol}, 2 \mathrm{eq}$ ) and $2 \mathrm{~b}(100 \mathrm{mg}, 0.38 \mathrm{mmol}, 1 \mathrm{eq})$ was stirred at $80^{\circ} \mathrm{C}$ for 4 hours. After cooling to room temperature, the crude was filtered and washed first with dichloromethane $(5 \mathrm{~mL})$ and then with diethyl ether $(10 \mathrm{~mL})$. Yield: $244 \mathrm{mg}, 89 \% .{ }^{1} \mathrm{H} N M R\left(\mathrm{D}_{2} \mathrm{O}, 25^{\circ} \mathrm{C}\right): \delta 1.35(\mathrm{t}, J=7.18 \mathrm{~Hz}$, $\left.12 \mathrm{H}, \mathrm{H}_{12}\right), 1.98\left(\mathrm{~m}, 4 \mathrm{H}, \mathrm{H}_{10}\right), 2.10\left(\mathrm{~m}, 4 \mathrm{H}, \mathrm{H}_{9}\right), 4.17\left(\mathrm{~m}, 8 \mathrm{H}, \mathrm{H}_{11}\right), 4.57\left(\mathrm{t}, J=7.80 \mathrm{~Hz}, 4 \mathrm{H}, \mathrm{H}_{8}\right)$, $5.27\left(\mathrm{~s}, 4 \mathrm{H}, \mathrm{H}_{13}\right), 7.36\left(\mathrm{~d}, J=8.50 \mathrm{~Hz}, 2 \mathrm{H}, \mathrm{H}_{5}\right), 7.57\left(\mathrm{t}, J=7.95 \mathrm{~Hz}, 2 \mathrm{H}, \mathrm{H}_{3}\right), 7.72(\mathrm{t}, J=7.70 \mathrm{~Hz}$, $\left.2 \mathrm{H}, \mathrm{H}_{6}\right), 7.93\left(\mathrm{~d}, J=8.43 \mathrm{~Hz}, 2 \mathrm{H}, \mathrm{H}_{4}\right), 9.44\left(\mathrm{~s}, 2 \mathrm{H}, \mathrm{H}_{1}\right) .{ }^{31} \mathrm{P} N M R\left(\mathrm{D}_{2} \mathrm{O}, 25^{\circ} \mathrm{C}\right): \delta 33.3 .{ }^{13} \mathrm{C} N M R$ $\left(\mathrm{D}_{2} \mathrm{O}, 25^{\circ} \mathrm{C}\right): \delta 15.6\left(\mathrm{~d}, J=5.9 \mathrm{~Hz}, \mathrm{C}_{12}\right), 21.0\left(\mathrm{~d}, J=141.6 \mathrm{~Hz}, \mathrm{C}_{10}\right), 22.0\left(\mathrm{~d}, J=4.55 \mathrm{~Hz}, \mathrm{C}_{9}\right), 46.5$ $\left(C_{13}\right), 47.1\left(d, J=19.4 \mathrm{~Hz}, C_{8}\right), 63.5\left(d, J=6.67 \mathrm{~Hz}, C_{11}\right), 111.6\left(C_{5}\right), 113.7\left(C_{4}\right), 127.9\left(C_{3}\right.$ and $\left.\mathrm{C}_{6}\right), 130.8\left(\mathrm{C}_{7}\right), 131.1\left(\mathrm{C}_{2}\right), 141.1\left(\mathrm{C}_{1}\right)$. IR (ATR) cm $\mathrm{cm}^{-1}: 2986 \mathrm{v}(\mathrm{C}-\mathrm{H}) \mathrm{ar}, 2898 \mathrm{v}(\mathrm{C}-\mathrm{H}), 1431(\mathrm{\delta}(\mathrm{C}=\mathrm{C})$, $\delta(\mathrm{C}=\mathrm{N}))$ ar, $1222(\mathrm{P}=\mathrm{O})$ st, 1020 (P-O-C)st, $758 \delta(\mathrm{C}-\mathrm{H})$ oop. HR-ESI-MS (DMSO): calculated: $\mathrm{m} / \mathrm{z}$ $=701.2055\left([\mathrm{M}+\mathrm{Na}]^{+}\right)$; found: $m / z=701.2064\left([\mathrm{M}+\mathrm{Na}]^{+}\right), 310.1442\left([\mathrm{M}-2 \mathrm{Br}]^{+2}\right)$. 

and $2 \mathrm{c}(250 \mathrm{mg}, 0.9 \mathrm{mmol}, 1 \mathrm{eq})$ was stirred at $80^{\circ} \mathrm{C}$ for 4 hours. After cooling to room temperature, the crude was solved in dichloromethane $(3 \mathrm{~mL})$ and diethyl ether $(25 \mathrm{~mL})$ was added to precipitate a white hygroscopic solid. Yield: $671 \mathrm{mg}, 92 \% .{ }^{1} \mathrm{H} \mathrm{NMR}\left(\mathrm{CDCl}_{3}, 25^{\circ} \mathrm{C}\right): \delta$ $1.28\left(\mathrm{t}, J=6.92 \mathrm{~Hz}, 12 \mathrm{H}, \mathrm{H}_{12}\right), 1.88\left(\mathrm{dt}, J=6.96 \mathrm{~Hz}, J=18.57 \mathrm{~Hz}, 4 \mathrm{H}, \mathrm{H}_{10}\right), 2.36\left(\mathrm{~m}, 4 \mathrm{H}, \mathrm{H}_{9}\right)$, $2.97\left(\mathrm{q}, J=6.98 \mathrm{~Hz}, 2 \mathrm{H}, \mathrm{H}_{14}\right), 4.06\left(\mathrm{~m}, 8 \mathrm{H}, \mathrm{H}_{11}\right), 4.68\left(\mathrm{t}, J=7.48 \mathrm{~Hz}, 4 \mathrm{H}, \mathrm{H}_{8}\right), 5.13(\mathrm{t}, J=7.49$ $\left.\mathrm{Hz}, 4 \mathrm{H}, \mathrm{H}_{13}\right), 7.58\left(\mathrm{t}, J=7.99 \mathrm{~Hz}, 2 \mathrm{H}, \mathrm{H}_{5}\right), 7.65\left(\mathrm{t}, J=7.48 \mathrm{~Hz}, 2 \mathrm{H}, \mathrm{H}_{4}\right), 7.78(\mathrm{~d}, J=8.31 \mathrm{~Hz}, 2 \mathrm{H}$, $\left.\mathrm{H}_{3}\right), 8.53\left(\mathrm{~d}, J=8.25 \mathrm{~Hz}, 2 \mathrm{H}, \mathrm{H}_{6}\right), 10.94\left(\mathrm{~s}, 2 \mathrm{H}, \mathrm{H}_{1}\right) .{ }^{31} \mathrm{P} \mathrm{NMR}\left(\mathrm{CDCl}_{3}, 25^{\circ} \mathrm{C}\right): \delta 29.8 .{ }^{13} \mathrm{C} \mathrm{NMR}$ $\left(\mathrm{CDCl}_{3}, 25^{\circ} \mathrm{C}\right): \delta 16.5\left(\mathrm{~d}, J=5.86 \mathrm{~Hz}, \mathrm{C}_{12}\right), 22.2\left(\mathrm{~d}, J=135.73 \mathrm{~Hz}, \mathrm{C}_{10}\right), 22.9\left(\mathrm{~d}, J=2.19 \mathrm{~Hz}, \mathrm{C}_{9}\right)$, $29.6\left(C_{14}\right), 44.5\left(C_{13}\right), 47.2\left(d, J=11.8 \mathrm{~Hz}, C_{8}\right), 62.1\left(d, J=6.57 \mathrm{~Hz}, C_{11}\right), 112.7\left(C_{3}\right), 115.2\left(C_{6}\right)$, $127.5\left(C_{5}\right), 127.8\left(C_{4}\right), 131.0\left(C_{7}\right), 131.6\left(C_{2}\right), 142.0\left(C_{1}\right)$. IR (ATR) cm ${ }^{-1}: 2978 v(C-H) a r, 2898$ $v(\mathrm{C}-\mathrm{H}), 1437(\delta(\mathrm{C}=\mathrm{C}), \delta(\mathrm{C}=\mathrm{N}))$ ar, $1229(\mathrm{P}=\mathrm{O})$ st, 1014 (P-O-C)st, $751 \delta(\mathrm{C}-\mathrm{H})$ oop. HR-ESI-MS (DMSO): calculated: $m / z=715.2212\left([\mathrm{M}+\mathrm{Na}]^{+}\right) ;$found: $m / z=715.2220\left([\mathrm{M}+\mathrm{Na}]^{+}\right), 317.1521$ $\left([\mathrm{M}-2 \mathrm{Br}]^{+2}\right)$.

\subsection{Synthesis and characterization of the complexes}

4.3.1 Dibromido-(1,1'-di(3-diethoxyphosphoryl)propyl-3,3'methylenedibenzimidazolin2,2'-diylidene)palladium(II) (mC1a). Palladium(II) acetate (102 $\mathrm{mg}, 0.45 \mathrm{mmol}, 1 \mathrm{eq}$ ) and ligand $3 a$ (350 mg, $0.46 \mathrm{mmol}, 1.01 \mathrm{eq}$ ) were dissolved in degassed DMSO (3 mL) in a roundbottom flask. The reddish mixture was stirred for $4 \mathrm{~h}$ at room temperature, $17 \mathrm{~h}$ at $40^{\circ} \mathrm{C}$ and, finally, $2 \mathrm{~h}$ at $120^{\circ} \mathrm{C}$. After cooling to room temperature, dichloromethane $(3 \mathrm{~mL})$ was added and the crude was filtered through a plug of celite. Then, diethyl ether $(50 \mathrm{~mL})$ was added to the yellow solution to precipitate the product as an orange powder. Yield: $268 \mathrm{mg}, 69 \% .{ }^{1} \mathrm{H}$ NMR (DMSO- $\left.d_{6}, 25^{\circ} \mathrm{C}\right): \delta 1.18\left(\mathrm{~m}, 12 \mathrm{H}, \mathrm{H}_{12}\right), 1.86\left(\mathrm{~m}, 4 \mathrm{H}, \mathrm{H}_{10}\right), 2.10\left(\mathrm{~m}, 4 \mathrm{H}, \mathrm{H}_{9}\right), 3.95(\mathrm{~m}, 8 \mathrm{H}$, $\left.\mathrm{H}_{11}\right), 4.60\left(\mathrm{~m}, 2 \mathrm{H}, \mathrm{H}_{8}\right), 5.01\left(\mathrm{~m}, 2 \mathrm{H}, \mathrm{H}_{8}\right), 6.79\left(\mathrm{~d}, J=13.98 \mathrm{~Hz}, 1 \mathrm{H}, \mathrm{H}_{13}\right), 7.35(\mathrm{~d}, J=14.19 \mathrm{~Hz}$, $\left.2 \mathrm{H}, \mathrm{H}_{13}\right), 7.45\left(\mathrm{~m}, 4 \mathrm{H}, \mathrm{H}_{4}\right.$ and $\left.\mathrm{H}_{5}\right), 7.80\left(\mathrm{~d}, J=7.99 \mathrm{~Hz}, 2 \mathrm{H}, \mathrm{H}_{3}\right), 8.24\left(\mathrm{~d}, J=7.92 \mathrm{~Hz}, 2 \mathrm{H}, \mathrm{H}_{6}\right)$. ${ }^{31} \mathrm{P}\left\{{ }^{1} \mathrm{H}\right\}$ NMR (DMSO- $\left.d_{6}, 25^{\circ} \mathrm{C}\right): \delta 31.01 .{ }^{13} \mathrm{C}\left\{{ }^{1} \mathrm{H}\right\}$ NMR (DMSO- $\left.d_{6}, 25^{\circ} \mathrm{C}\right): \delta 16.7(\mathrm{~d}, J=5.23 \mathrm{~Hz}$, $C_{12}$ ), 22.09 (d, $\left.J=140.28 \mathrm{~Hz}, C_{10}\right), 23.1\left(C_{9}\right), 48.5\left(C_{8}\right), 58.0\left(C_{13}\right), 61.5\left(t, J=7.25 \mathrm{~Hz}, C_{11}\right)$, $111.8\left(C_{6}\right), 112.2\left(C_{3}\right), 124.5\left(C_{5}\right), 124.7\left(C_{4}\right), 133.5\left(C_{7}\right), 133.72\left(C_{2}\right), 170.9\left(C_{1}\right)$. IR (ATR) cm ${ }^{-1}:$ $3093 v(\mathrm{C}-\mathrm{H})$ ar, $2972 v(\mathrm{C}-\mathrm{H})$, 1451, $1397(\delta(\mathrm{C}=\mathrm{C}), \delta(\mathrm{C}=\mathrm{N}))$ ar, $1222(\mathrm{P}=\mathrm{O})$ st, 1014 (P-O-C)st, 757 $\delta(\mathrm{C}-\mathrm{H})$ oop. HR-ESI-MS (DMSO): calculated: $\mathrm{m} / z=892.9866\left([\mathrm{M}+\mathrm{Na}]^{+}\right)$; found: $\mathrm{m} / z=892.9868$ $\left([\mathrm{M}+\mathrm{Na}]^{+}\right), 791.0794\left([\mathrm{M}-\mathrm{Br}]^{+}\right)$.

4.3.2 Dibromido-(1,1'-di(3-diethoxyphosphoryl)propyl-3,3'ethylenedibenzimidazolin-2,2'diylidene)palladium(II) ( $m$ C1 $b$ ). Palladium(II) acetate ( $43 \mathrm{mg}, 0.19 \mathrm{mmol}, 1 \mathrm{eq}$ ) and ligand $\mathbf{3 b}$ (150 mg, $0.19 \mathrm{mmol}, 1.01 \mathrm{eq}$ ) were dissolved in degassed DMSO $(3 \mathrm{~mL}$ ) in a round-bottom flask. The reddish mixture was stirred for $4 \mathrm{~h}$ at room temperature, $17 \mathrm{~h}$ at $40^{\circ} \mathrm{C}$ and, finally, $2 \mathrm{~h}$ at $120^{\circ} \mathrm{C}$. After cooling to room temperature, dichloromethane $(3 \mathrm{~mL})$ was added and the crude was filtered through a plug of celite. Then, diethyl ether $(50 \mathrm{~mL})$ was added to the yellow solution to precipitate the product as pale yellow powder. Yield: $115 \mathrm{mg}, 68 \%$. ${ }^{1} \mathrm{H}$ NMR (DMSO- $\left.d_{6}, 25^{\circ} \mathrm{C}\right): \delta 1.22\left(\mathrm{~m}, 12 \mathrm{H}, \mathrm{H}_{12}\right), 1.94\left(\mathrm{~m}, 4 \mathrm{H}, \mathrm{H}_{13}\right), 2.10\left(\mathrm{~m}, 2 \mathrm{H}, \mathrm{H}_{3}\right), 2.22(\mathrm{~m}, 2 \mathrm{H}$, 
$\left.\mathrm{H}_{3}\right), 4.00\left(\mathrm{~m}, 8 \mathrm{H}, \mathrm{H}_{11}\right), 4.72\left(\mathrm{~m}, 2 \mathrm{H}, \mathrm{H}_{10}\right), 4.82\left(\mathrm{~m}, 2 \mathrm{H}, \mathrm{H}_{10}\right), 5.07\left(\mathrm{~m}, 2 \mathrm{H}, \mathrm{H}_{2}\right), 5.65\left(\mathrm{~m}, 2 \mathrm{H}, \mathrm{H}_{2}\right)$, $7.39\left(\mathrm{~m}, 4 \mathrm{H}, \mathrm{H}_{5}\right.$ and $\left.\mathrm{H}_{8}\right), 7.75\left(\mathrm{~m}, 4 \mathrm{H}, \mathrm{H}_{6}\right.$ and $\left.\mathrm{H}_{7}\right) .{ }^{31} \mathrm{P}\left\{{ }^{1} \mathrm{H}\right\}$ NMR (DMSO- $\left.d_{6}, 25^{\circ} \mathrm{C}\right): \delta 31.37$. ${ }^{13} \mathrm{C}\left\{{ }^{1} \mathrm{H}\right\}$ NMR (DMSO- $\left.d_{6}, 25^{\circ} \mathrm{C}\right): \delta 16.3\left(\mathrm{~d}, J=5.29 \mathrm{~Hz}, \mathrm{C}_{12}\right), 21.7\left(\mathrm{~d}, J=140.79 \mathrm{~Hz}, \mathrm{C}_{13}\right), 22.2(\mathrm{~d}$, $\left.J=3.86 \mathrm{~Hz}, C_{3}\right), 43.9\left(C_{2}\right), 48.7\left(C_{10}\right), 61.1\left(t, J=5.93 \mathrm{~Hz}, C_{11}\right), 111.3\left(C_{6}\right.$ and $\left.C_{7}\right), 123.6\left(C_{5}\right)$, $123.8\left(C_{8}\right), 133.3\left(C_{4}\right), 133.9\left(C_{9}\right)$. IR (ATR) cm ${ }^{-1}: 2978 v(C-H), 1464,1404(\delta(C=C), \delta(C=N))$ ar, 1229 (P=O)st, 1006 (P-O-C)st, $751 \delta(\mathrm{C}-\mathrm{H})$ oop. HR-ESI-MS (DMSO): calculated: $\mathrm{m} / z=907.0023$ $\left([\mathrm{M}+\mathrm{Na}]^{+}\right)$; found: $m / z=907.0019\left([\mathrm{M}+\mathrm{Na}]^{+}\right), 805.0943\left([\mathrm{M}-\mathrm{Br}]^{+}\right)$.

\subsubsection{Dibromido-(1,1'- di(3-diethoxyphosphoryl)propyl-3,3'propylenedibenzimidazolin-} 2,2'-diylidene)palladium(II) (mC1c). Palladium(II) acetate $(69 \mathrm{mg}, 0.31 \mathrm{mmol}, 1 \mathrm{eq}$ ) and ligand $3 c$ ( $250 \mathrm{mg}, 0.31 \mathrm{mmol}, 1.01 \mathrm{eq})$ were dissolved in degassed DMSO (3 mL) in a roundbottom flask. The reddish mixture was stirred for $4 \mathrm{~h}$ at room temperature, $17 \mathrm{~h}$ at $40^{\circ} \mathrm{C}$ and, finally, $2 \mathrm{~h}$ at $120^{\circ} \mathrm{C}$. After cooling to room temperature, dichloromethane $(3 \mathrm{~mL})$ was added and the crude was filtered through a plug of celite. Then, diethyl ether $(50 \mathrm{~mL})$ was added to the yellow solution to precipitate the product as a pale green powder. Yield: $235 \mathrm{mg}, 85 \%$. ${ }^{1} \mathrm{H}$ NMR (DMSO- $\left.d_{6}, 25^{\circ} \mathrm{C}\right): \delta 1.21\left(\mathrm{dt}, J=12.97 \mathrm{~Hz}, J=16.72 \mathrm{~Hz}, 12 \mathrm{H}, \mathrm{H}_{12}\right), 1.87\left(\mathrm{~m}, 2 \mathrm{H}, \mathrm{H}_{9}\right.$ and $\left.1 \mathrm{H}, \mathrm{H}_{14}\right), 2.06\left(\mathrm{~m}, 4 \mathrm{H}, \mathrm{H}_{10}\right), 2.32\left(\mathrm{~m}, 2 \mathrm{H}, \mathrm{H}_{9}\right), 2.55\left(\mathrm{~m}, 1 \mathrm{H}, \mathrm{H}_{14}\right), 4.00\left(\mathrm{~m}, 8 \mathrm{H}, \mathrm{H}_{11}\right), 4.55(\mathrm{td}, J=$ $\left.3.99 \mathrm{~Hz}, J=10.51 \mathrm{~Hz}, 2 \mathrm{H}, \mathrm{H}_{8}\right), 4.86\left(\mathrm{dd}, J=5.52 \mathrm{~Hz}, J=14.50 \mathrm{~Hz}, 2 \mathrm{H}, \mathrm{H}_{13}\right), 5.05\left(\mathrm{~m}, 2 \mathrm{H}, \mathrm{H}_{8}\right)$, $5.26\left(\mathrm{dd}, J=11.87 \mathrm{~Hz}, J=14.53 \mathrm{~Hz}, 2 \mathrm{H}, \mathrm{H}_{13}\right), 7.27\left(\mathrm{dd}, J=3.09 \mathrm{~Hz}, J=6.02 \mathrm{~Hz}, 4 \mathrm{H}, \mathrm{H}_{3}\right.$ and $\left.\mathrm{H}_{6}\right)$, $7.64\left(\mathrm{~m}, 4 \mathrm{H}, \mathrm{H}_{4}\right.$ and $\left.\mathrm{H}_{5}\right) .{ }^{31} \mathrm{P}\left\{{ }^{1} \mathrm{H}\right\}$ NMR (DMSO- $\left.d_{6}, 25^{\circ} \mathrm{C}\right): \delta 31.37 .{ }^{13} \mathrm{C}\left\{{ }^{1} \mathrm{H}\right\}$ NMR (DMSO- $d_{6}$, $25^{\circ} \mathrm{C}$ ): $\delta 16.4\left(\mathrm{dd}, J=4.39 \mathrm{~Hz}, J=5.72 \mathrm{~Hz}, \mathrm{C}_{12}\right), 21.81\left(\mathrm{~d}, J=3.86 \mathrm{~Hz}, \mathrm{C}_{9}\right), 21.88(\mathrm{~d}, J=139.59$ $\left.\mathrm{Hz}, \mathrm{C}_{10}\right), 29.15\left(\mathrm{C}_{14}\right), 48.38\left(\mathrm{~d}, J=19.92 \mathrm{~Hz}, \mathrm{C}_{8}\right), 48.76\left(\mathrm{C}_{13}\right), 61.16(\mathrm{dd}, J=6.72 \mathrm{~Hz}, J=12.21$ $\left.\mathrm{Hz}, \mathrm{C}_{11}\right), 110.86\left(\mathrm{C}_{5}\right), 111.28\left(\mathrm{C}_{4}\right), 123.30\left(\mathrm{C}_{6}\right), 123.50\left(\mathrm{C}_{3}\right), 132.88\left(\mathrm{C}_{7}\right), 133.99\left(\mathrm{C}_{2}\right), 173.49$ $\left(C_{1}\right)$. IR (ATR) cm $\mathrm{cm}^{-1}: 2986 \mathrm{v}(\mathrm{C}-\mathrm{H}), 1457,1417(\delta(\mathrm{C}=\mathrm{C}), \delta(\mathrm{C}=\mathrm{N}))$ ar, 1229 (P=O)st, 1014 (P-O-C)st, $751 \delta(\mathrm{C}-\mathrm{H})$ oop. HR-ESI-MS (DMSO): calculated: $\mathrm{m} / \mathrm{z}=921.0180\left([\mathrm{M}+\mathrm{Na}]^{+}\right)$; found: $\mathrm{m} / \mathrm{z}=$ $921.0165\left([\mathrm{M}+\mathrm{Na}]^{+}\right), 819.1093\left([\mathrm{M}-\mathrm{Br}]^{+}\right)$.

\subsection{Synthesis and characterization of the hybrid nanomaterials}

mC1a-TiO 2 : A solution of $\mathbf{m C 1 a}(16.3 \mathrm{mg}, 0.02 \mathrm{mmol}, 0.002 \mathrm{eq})$ in dichloromethane $(4 \mathrm{~mL})$ was added to an ACE pressure tube containing $\mathrm{TiO}_{2} \mathrm{P}-25$ (740 mg, $\left.9.4 \mathrm{mmol}, 1 \mathrm{eq}\right)$. The reaction mixture was kept under vigorous stirring at $45^{\circ} \mathrm{C}$ overnight. Then, the orange powder was filtered off and washed with dichloromethane $(3 \times 10 \mathrm{~mL})$, methanol $(3 \times 10 \mathrm{~mL})$ and diethyl ether $(3 \times 10 \mathrm{~mL})$. Finally, the product was dried under vacuum at $120^{\circ} \mathrm{C}$ for $6 \mathrm{~h}$. Recovered: $709 \mathrm{mg} .{ }^{31} \mathrm{P}$ HPDEC NMR $\left(25^{\circ} \mathrm{C}, \mathrm{ppm}\right): \delta 26.10,31.55$. FT-IR $\left(\mathrm{ATR}, \mathrm{cm}^{-1}\right): 1037(\mathrm{P}-$ O-Ti) st. ICP-OES (w/w\%): Pd, 0.23; Ti, 56.12; P, 0.11.

mC1b-TiO ${ }_{2}$ : A solution of $\mathbf{m C 1 b}(16.4 \mathrm{mg}, 0.02 \mathrm{mmol}, 0.002 \mathrm{eq})$ in dichloromethane $(4 \mathrm{~mL})$ was added to an ACE pressure tube containing $\mathrm{TiO}_{2} \mathrm{P}-25$ (740 mg, $\left.9.4 \mathrm{mmol}, 1 \mathrm{eq}\right)$. The reaction mixture was kept under vigorous stirring at $45^{\circ} \mathrm{C}$ overnight. Then, the powder was filtered off and washed with dichloromethane $(3 \times 10 \mathrm{~mL})$, methanol $(3 \times 10 \mathrm{~mL})$ and diethyl ether $(3 \times 10 \mathrm{~mL})$. Finally, the product was dried under vacuum at $120^{\circ} \mathrm{C}$ for $6 \mathrm{~h}$. Recovered: $693 \mathrm{mg} .{ }^{31} \mathrm{P}$ HPDEC NMR $\left(25^{\circ} \mathrm{C}, \mathrm{ppm}\right): \delta 26.02,32.41$. FT-IR (ATR, $\left.\mathrm{cm}^{-1}\right): 1052$ (P-O-Ti) st. ICPOES (w/w\%): Pd, 0.21; Ti, 54.38; P, 0.11 . 
mC1c- $\mathrm{TiO}_{2}$ : A solution of $\mathrm{mC1c}(16.9 \mathrm{mg}, 0.02 \mathrm{mmol}, 0.002 \mathrm{eq})$ in dichloromethane $(4 \mathrm{~mL})$ was added to an ACE pressure tube containing $\mathrm{TiO}_{2} \mathrm{P}-25$ (740 mg, $\left.9.4 \mathrm{mmol}, 1 \mathrm{eq}\right)$. The reaction mixture was kept under vigorous stirring at $45^{\circ} \mathrm{C}$ overnight. Then, the powder was filtered off and washed with dichloromethane $(3 \times 10 \mathrm{~mL})$, methanol $(3 \times 10 \mathrm{~mL})$ and diethyl ether $(3 \times 10 \mathrm{~mL})$. Finally, the product was dried under vacuum at $120^{\circ} \mathrm{C}$ for $6 \mathrm{~h}$. Recovered: $685 \mathrm{mg} .{ }^{31} \mathrm{P}$ HPDEC NMR $\left(25^{\circ} \mathrm{C}, \mathrm{ppm}\right): \delta 25.24,31.81$. FT-IR (ATR, $\left.\mathrm{cm}^{-1}\right): 1052$ (P-O-Ti) st. ICPOES (w/w\%): Pd, 0.19; Ti, 55.28; P, 0.10.

3a- $\mathrm{TiO}_{2}$ : A solution of $3 \mathrm{a}(15 \mathrm{mg}, 0.019 \mathrm{mmol}, 0.002 \mathrm{eq})$ in dichloromethane $(4 \mathrm{~mL})$ was added to an ACE pressure tube containing $\mathrm{TiO}_{2} \mathrm{P}-25(600 \mathrm{mg}, 7.6 \mathrm{mmol}, 1 \mathrm{eq})$. The reaction mixture was kept under vigorous stirring at $45^{\circ} \mathrm{C}$ overnight. Then, the powder was filtered off and washed with dichloromethane $(3 \times 10 \mathrm{~mL})$, methanol $(3 \times 10 \mathrm{~mL})$ and diethyl ether $(3$ $x 10 \mathrm{~mL}$ ). Finally, the product was dried under vacuum at $120^{\circ} \mathrm{C}$ for $6 \mathrm{~h}$. Recovered: $591 \mathrm{mg}$. ${ }^{31} \mathrm{P}$ HPDEC NMR $\left(25^{\circ} \mathrm{C}, \mathrm{ppm}\right): \delta 25.9,31.1$. FT-IR $\left(\right.$ ATR, $\left.\mathrm{cm}^{-1}\right): 1052$ (P-O-Ti) st. ICP-OES (w/w\%): Ti, 56.28; P, 0.29 .

\subsection{Catalytic experiments}

\subsubsection{Catalytic studies for Suzuki-Miyaura reactions}

In glass tubes of a Radleys Carousel 12 Plus Station ${ }^{\mathrm{TM}}$ fitted with a water-cooled aluminum reflux head and septa, $16 \mathrm{~mL}$ of an absolute EtOH solution containing $p$ halogenoacetophenone (0.05 M, 1 eq), phenylboronic acid (0.06 M, 1.2 eq) and MeONa $(0.075 \mathrm{M}, 1.5 \mathrm{eq})$ were added. The reaction mixtures were stirred and heated at $25^{\circ} \mathrm{C}$ or $60^{\circ} \mathrm{C}$ under nitrogen atmosphere for 30 minutes. Then, the palladium catalyst $\left(8 \times 10^{-4} \mathrm{mmol} \mathrm{Pd}, 5\right.$ $x 10^{-5} \mathrm{M}, 0.001 \mathrm{eq}$ ) was added. The mixture was vigorously stirred and kept at $60^{\circ} \mathrm{C}$ for $1 \mathrm{~h}$ under nitrogen. Then, an aliquot $(c a .0 .5 \mathrm{~mL})$ of the reaction crude was taken at different reaction times and quenched in a vial filled with water/ethyl acetate mixture $(2: 1.5,3.5 \mathrm{~mL})$ and with naphthalene $(0.09 \mathrm{mmol})$ as standard.

The organic phase was analyzed by GC and GC-MS.

All products gave analytical data in agreement with those reported in the literature: $\{p$ acetylbiphenyl [92-91-1], 2-methoxybiphenyl [86-26-0], 4-methoxybiphenyl [613-37-6], 4phenyltoluene [644-08-6], 2-chloro-1,1-biphenyl [2051-60-7], 1-phenylnaphthalene [605-027], 1-phenylpyrene [5101-27-9], 4-phenylisoquinoline [19571-30-3], 3-phenylquinoline [1666-96-2], 2-phenylnaphthalene [612-94-2], 2-phenyl-9H-fluorene [28065-98-7], 3methoxybiphenyl [2113-56-6], 2-hydroxybiphenyl [90-43-7], 3,4-dimethoxy-1,1'-biphenyl [17423-55-1], 1,3-dimethoxy-5-phenylbenzene [64326-17-6], 4-(trifluoromethyl)-1,1'biphenyl [398-36-7], 3-(trifluoromethyl)biphenyl [366-04-1], 4-cyanobiphenyl [2920-38-9], biphenyl [613-37-6], 3-fluoro-[1,1'-biphenyl]-4-carbonitrile [503177-15-9], 4-fluorobiphenyl [324-74-3], 2,3,4,5,6-pentafluorobiphenyl [784-14-5], 2-([1,1'-biphenyl]-3-yl)pyridine [458541-39-4], 5-phenyl- $1 H$-indole [66616-72-6], 7-phenyl- $1 H$-indole [1863-21-4]\}. For TEM analyses, a drop of the crude mixture was deposited on the holey carbon-covered copper.

In order to obtain the iTOF values, the evolved mmol of $p$-acetylbiphenyl divided by $8 \times 10^{4}$ $\mathrm{mmol}$ of Pd vs time (in minutes) was plotted. Thus, a polynomial equation was fitted for the 
region 0-3 min and the first derivative was calculated. Finally, the iTOF values were obtained for $x=0$ for the first derivative equation. TON values were calculated dividing the evolved mmol of $p$-acetylbiphenyl by $8 \times 10^{-4} \mathrm{mmol}$ of Pd. TOF values were calculated dividing the TON values by the required time (in hours) to achieve the maximum conversion for each catalyst.

\subsubsection{Procedures for recycling}

Method A. After calculating the remaining volume, the appropriate amount of a stock solution of $p$-bromoacetophenone, phenylboronic acid and MeONa in EtOH (0.2 M, 0.24 M and $0.3 \mathrm{M}$, respectively) was introduced (to reach final concentrations of $0.05 \mathrm{M}, 0.06 \mathrm{M}$ and $0.075 \mathrm{M}$, respectively) in a sealed Glass catalytic reactor of the Radleys Carousel 12 Plus Station $^{\mathrm{TM}}$ fitted with a water-cooled aluminum reflux head and septa. The station was preheated at $60^{\circ} \mathrm{C}$. The reaction was conducted under vigorous stirring and followed by GC analysis until completion. Then, a new aliquot of the stock solution was added keeping the same concentration of the reagents as in the previous runs.

Method B. After determining the Pd content in the hybrid catalyst, in a two-neck $250 \mathrm{~mL}$ round-bottom flask fitted with a reflux condenser and septa, the appropriate amounts of $p$ bromoacetophenone, phenylboronic acid and $\mathrm{MeONa}$ and $\mathrm{EtOH}$ were introduced to reach final concentrations of $0.05 \mathrm{M}, 0.06 \mathrm{M}$ and $0.075 \mathrm{M}$, respectively. The reaction mixture was preheated at $60^{\circ} \mathrm{C}$. Then, the hybrid catalyst was added at once. The reaction was conducted under vigorous stirring and followed by GC analysis until completion. Then, after cooling to room temperature, the reaction crude was centrifuged to isolate the hybrid catalyst as a powder. Furthermore, the catalyst was washed with acetone and dried under vacuum for further analyses and reuse by using the same Pd loading.

\subsubsection{Catalytic performance study for $\mathrm{C} 1 \mathrm{c}$ in the presence of $3 \mathrm{a}-\mathrm{TiO}_{2}$}

In a glass tube of a Radleys Carousel 12 Plus Station ${ }^{\mathrm{TM}}$ fitted with a water-cooled aluminum reflux head and septa, $70 \mathrm{~mL}$ of an absolute $\mathrm{EtOH}$ solution containing $p$-bromoacetophenone ( $700 \mathrm{mg}, 3.5 \mathrm{mmol}, 0.05 \mathrm{M}, 1 \mathrm{eq}$ ), phenylboronic acid (515 mg, $4.2 \mathrm{mmol}, 0.06 \mathrm{M}, 1.2 \mathrm{eq}$ ), MeONa (285 mg, $5.3 \mathrm{mmol}, 0.075 \mathrm{M}, 1.5 \mathrm{eq})$ and $3 \mathrm{a}-\mathrm{TiO}_{2}(74.8 \mathrm{mg}, 0.001 \mathrm{eq}$ ligand-topalladium) were added. The reaction mixtures were stirred and heated at $60^{\circ} \mathrm{C}$ or $25^{\circ} \mathrm{C}$ under nitrogen atmosphere for 30 minutes. Then, the palladium catalyst $\mathbf{C} 1 \mathrm{c}\left(3.5 \times 10^{-3} \mathrm{mmol} \mathrm{Pd}, 5\right.$ $x 10^{-5} \mathrm{M}, 0.001 \mathrm{eq}$ ) was added from a stock solution. The mixture was vigorously stirred and kept at $60^{\circ} \mathrm{C}$ for $1 \mathrm{~h}$ under nitrogen. Then, an aliquot $(c a .0 .5 \mathrm{~mL})$ of the reaction crude was taken at different reaction times and quenched in a vial filled with $\mathrm{H}_{2} \mathrm{O} /$ EtOAc mixture (2:1.5, $3.5 \mathrm{~mL})$ and with naphthalene $(0.09 \mathrm{mmol})$ as standard. The organic phase was analyzed by GC and GC-MS.

\subsubsection{Procedure for the leaching studies by hot-filtration}


In glass tubes of the Radleys Carousel 12 Plus Station ${ }^{\mathrm{TM}}$ fitted with a water-cooled aluminum reflux head and septa, $16 \mathrm{~mL}$ of an absolute $\mathrm{EtOH}$ solution containing $p$-bromoacetophenone (160 mg, $0.8 \mathrm{mmol}, 0.05 \mathrm{M}, 1 \mathrm{eq}$ ), phenylboronic acid (118 mg, $0.96 \mathrm{mmol}, 0.06 \mathrm{M}, 1.2 \mathrm{eq}$ ) and MeONa (65 mg, $1.2 \mathrm{mmol}, 0.075 \mathrm{M}, 1.5 \mathrm{eq}$ ) were added. Next, the reaction mixtures were stirred and heated at $60^{\circ} \mathrm{C}$ under nitrogen atmosphere for 30 minutes. Then, the palladium catalyst $\left(8 \times 10^{-4} \mathrm{mmol} \mathrm{Pd}, 5 \times 10^{-5} \mathrm{M}, 0.001 \mathrm{eq}\right)$ was added. The reaction was conducted under vigorous stirring for $15 \mathrm{~min}$ of reaction. The supernatant solution was filtered through a cannula with a microglass Whatman ${ }^{\circledR}$ filter and Celite ${ }^{\circledR}$ (in order to remove all fine particles). The reaction was monitored by GC over the total period and the results compared to a standard catalytic reaction.

\subsection{TEM analyses}

For the hybrid $\mathrm{mCla}^{-\mathrm{c}-\mathrm{TiO}_{2}}$ materials, the as-prepared powder was dispersed in EtOH followed by deposition of some drops under the holey carbon-covered copper grid. For catalytic tests, after $1 \mathrm{~h}$ of catalytic reaction, a drop of the crude mixture was deposited under the holey carbon-covered copper grid for TEM analysis. $\mathbf{m C 1} \mathbf{C}-\mathrm{TiO}_{2}$ catalysts were dispersed in $\mathrm{EtOH}$ and a drop was deposited under the holey carbon-covered copper grids.

\section{Declaration of competing interest}

The authors declare that there is no conflict of interest.

\section{Acknowledgements}

Financial support from ANR research program is gratefully acknowledged (HYPERCAT, contract N ANR-18-CE07-0021-03). We thank Dr V. Meille and Dr C. de Bellefon (CP2M, Lyon) for fruitful discussions. We kindly acknowledge L. Burel (TEM, IRCELYON, N. Bonnet and P. Mascunan (ICP-OES, IRCELYON), Dr A. Demessence (UV-vis, IRCELYON), Dr D. Aldakov (XPS, SYMMES CEA Grenoble) and the Centre Commun de Spectrométrie de Masse (University Lyon 1) for analyses and discussions.

\section{Appendix A. Supplementary material}

Supplementary data associated with this article can be found, in the online version, at DOI:

\section{References}

\footnotetext{
${ }^{1}$ S. Kotha, K. Lahiri, D. Kashinath, Recent applications of the Suzuki-Miyaura cross-coupling reaction in organic synthesis Tetrahedron 58 (2002) 9633-9695.

${ }^{2}$ A. Ganesan, New tools for parallel automated chemistry Drug Discovery Today 6 (2001) 238-241.

${ }^{3}$ L. Yin, J. Liebscher, Carbon-carbon coupling reactions catalyzed by heterogeneous palladium catalysts, Chem. Rev. 107 (2007) 133-173.

${ }^{4}$ V. Polshettiwar, C. Len, A. Fihri, Silica-supported palladium: Sustainable catalysts for cross-coupling reactions, Coord. Chem. Rev. 253 (2009) 2599-2626.
} 
${ }^{5}$ M. Lamblin, L. Nassar-Hardy, J. Hierso, E. Fouquet, F. Felpin, Recyclable heterogeneous palladium catalysts in pure water: Sustainable developments in Suzuki, Heck, Sonogashira and Tsuji-Trost reactions, Adv. Synth. Catal. 352 (2010) 33-79.

${ }^{6}$ S. Navalón, M. Álvaro, H. García, Polymer- and Ionic Liquid-Containing Palladium: Recoverable Soluble CrossCoupling Catalysts ChemCatChem 5 (2013) 3460-3480.

7 K.V.S. Ranganath, S. Onitsuka, A.K. Kumar, J. Inanaga, Recent progress of N-heterocyclic carbenes in heterogeneous catalysis Catal. Sci. Technol. 3 (2013) 2161-2181.

${ }^{8}$ J. De Tovar, F. Rataboul, L. Djakovitch, Insights into the Suzuki-Miyaura Reaction Catalyzed by Novel Pd Carbene Complexes. Are Palladium - Tetracarbene Entities the Key Active Species? ChemCatChem 12 (2020) 5797-5808.

${ }^{9}$ A. Wolfson, O. Levy-Ontman, Recent developments in the immobilization of palladium complexes on renewable polysaccharides for Suzuki-Miyaura cross-coupling of halobenzenes and phenylboronic acids Catalysts 10 (2020) 136.

${ }^{10}$ Topics in Current Chemistry, Immobilized Catalysts, A. Kirschning, Editor.; Springer-Verlag Berlin Heidelberg: 2004 vol. 242.

${ }^{11}$ F. Amoroso, S. Colussi, A. Del Zotto, J. Llorca, A. Trovarelli, Room-Temperature Suzuki-Miyaura Reaction Catalyzed by Pd Supported on Rare Earth Oxides: Influence of the Point of Zero Charge on the Catalytic Activity Catal. Lett. 143 (2013) 547-554.

${ }^{12}$ A. Del Zotto, D. Zuccaccia, Metallic palladium, PdO, and palladium supported on metal oxides for the SuzukiMiyaura cross-coupling reaction: a unified view of the process of formation of the catalytically active species in solution Catal. Sci. Technol. 7 (2017) 3934-3951.

${ }^{13}$ A. Del Zotto, S. Colussi, A. Trovarelli, Pd/REOs catalysts applied to the Suzuki-Miyaura coupling. A comparison of their catalytic performance and reusability Inorganic Chim. Acta 470 (2018) 275-283.

14 P.O. Asekunowo, R.A. Haque, M.R. Razali, S. Budagumpi, Benzimidazole-based silver(I)-N-heterocyclic carbene complexes as anti-bacterials: synthesis, crystal structures and nucleic acids interaction studies Appl. Organometal. Chem. 29 (2015) 126-137.

${ }^{15}$ F. Gómez-Villarraga, J. De Tovar, M. Guerrero, P. Nolis, T. Parella, P. Lecante, N. Romero, L. Escriche, R. Bofill, J. Ros, X. Sala, K. Philippot, J. García-Antón, Dissimilar catalytic behavior of molecular or colloidal palladium systems with a new NHC ligand Dalton Trans. 46 (2017) 11768-11778.

${ }^{16}$ T. Scherg, S.K. Schneider, S.G. Frey, J. Schwarz, E. Herdtweck, W.A. Hermann, Bridged imidazolium salts used as precursors for chelating carbene complexes of palladium in the Mizoroki-Heck reaction Synlett 18 (2006) 2894-2907.

17 R. Jothibasu, H.V. Huynh, Syntheses and catalytic activities of $\mathrm{Pd}(\mathrm{II})$ dicarbene and hetero-dicarbene complexes J. Organomet. Chem. 696 (2011) 3369-3375.

${ }^{18}$ R. Boissezon, J. Muller, V. Beaugeard, S. Monge, J.-J. Robin, Organophosphonates as anchoring agents onto metal oxide-based materials: synthesis and applications RSC Adv. 4 (2014) 35690-35707.

${ }^{19}$ S.A. Paniagua, A.J. Giordano, O.L. Smith, S. Barlow, H. Li, N.R. Armstrong, J.E. Pemberton, J.-L. Brédas, D. Ginger, S.R. Marder, Phosphonic Acids for Interfacial Engineering of Transparent Conductive Oxides Chem. Rev. 12 (2016) 7117-7158.

20 J. De Tovar, N. Romero, S. A. Denisov, R. Bofill, C. Gimbert-Suriñach, D. Ciuculescu-Pradins, S. Drouet, A. Llobet, P. Lecante, V. Colliere, Z. Freixa, N. McClenaghan, C. Amiens, J. García-Antón, K. Philippot, X. Sala, Lightdriven water oxidation using hybrid photosensitizer-decorated $\mathrm{Co}_{3} \mathrm{O}_{4}$ nanoparticles Mater. Today Energy 9 (2018) 506-515.

${ }^{21}$ M.B. Mitchell, V.N. Sheinker, E.A. Mintz, Adsorption and Decomposition of Dimethyl Methanephosphonate on Metal Oxides J. Phys. Chem. B 101 (1997) 11192-11203.

${ }^{22}$ G. Guerrero, P.H. Mutin, A. Vioux, Anchoring of Phosphonate and Phosphinate Coupling Molecules on Titania Particles Chem. Mater. 13 (2001) 4367-4373.

${ }^{23}$ A. Bachinger, S. Ivanovici, G. Kickelbick, Formation of Janus $\mathrm{TiO}_{2}$ nanoparticles by a pickering emulsion approach applying phosphonate coupling agents J. Nanosci. Nanotechnol. 11 (2011) 8599-8608.

${ }^{24}$ L. Djakovitch, K. Koehler, J.G. De Vries, Nanoparticles and Catalysis, The Role of Palladium Nanoparticles as Catalyst for Carbon - Carbon Coupling Reactions, D. Astruc, Editor.; Wiley-VCH: Weinheim, 2008 pp 303-348.

${ }^{25}$ N.T.S. Phan, M. Van Der Sluys, C.W. Jones, On the nature of the active species in palladium catalyzed Mizoroki-Heck and Suzuki-Miyaura couplings - homogeneous or heterogeneous catalysis, a critical review Adv. Synth. Catal. 348 (2006) 609-679. 
${ }^{26}$ G. Borja, A. Monge-Marcet, R. Pleixats, T. Parella, X. Cattoën, M. Wong Chi Man, Recyclable Hybrid SilicaBased Catalysts Derived from Pd-NHC Complexes for Suzuki, Heck and Sonogashira Reactions Eur. J. Org. Chem. (2012), 3625-3635.

27 J. M. Richardson, C.W. Jones, Strong evidence of solution-phase catalysis associated with palladium leaching from immobilized thiols during Heck and Suzuki coupling of aryl iodides, bromides, and chlorides J. Catal. 251 (2007) 80-93.

${ }^{28}$ S. Chouzier, M. Gruber, L. Djakovitch, New hetero-bimetallic Pd-Cu catalysts for the one-pot indole synthesis via the Sonogashira reaction J. Mol. Catal. A: Chem. 212 (2004) 43-52.

${ }^{29}$ L. Djakovitch, P. Rollet, Sonogashira cross-coupling reactions catalyzed by copper-free palladium zeolites Adv. Synth. Catal. 346 (2004) 1782-1792.

${ }^{30}$ J. A. Byrne, B. R. Eggins, Photoelectrochemistry of oxalate on particulate $\mathrm{TiO}_{2}$ electrodes J. Electroanal. Chem. 457 (1998) 61-72.

${ }^{31}$ A. Eskandari, M. Jafarpour, A. Rezaeifard, M. Salimi, Supramolecular photocatalyst of palladium (II) encapsulated within dendrimer on $\mathrm{TiO}_{2}$ nanoparticles for photo-induced Suzuki-Miyaura and Sonogashira cross-coupling reactions Appl. Organometal. Chem. 33 (2019) e5093.

${ }^{32}$ M. Sakar, R.M. Prakashi, T.-O. Do, Insights into the $\mathrm{TiO}_{2}$-based photocatalytic systems and their mechanisms Catalysts 9 (2019) 680.

${ }^{33}$ R. Santhosh Reddy, R. Mahamadali Shaikh, V. Rawat, P. U. Karabal, G. Dewkar, G. Suryavanshi, A. Sudalai, A Novel Synthesis and Characterization of Titanium Superoxide and its Application in Organic Oxidative Processes Catal. Suv. Asia 14 (2010), 21-32. 